\title{
Emx2 and Pax6 Function in Cooperation with Otx2 and Otx1 to Develop Caudal Forebrain Primordium That Includes Future Archipallium
}

\author{
Jun Kimura, ${ }^{1 *}$ Yoko Suda, ${ }^{1 \star}$ Daisuke Kurokawa, ${ }^{1}$ Zakir M. Hossain, ${ }^{1}$ Miwa Nakamura, ${ }^{1}$ Maiko Takahashi, ${ }^{1}$ \\ Akemi Hara, ${ }^{2}$ and Shinichi Aizawa ${ }^{1}$ \\ Laboratories for ${ }^{1}$ Vertebrate Body Plan and ${ }^{2}$ Animal Resources and Genetic Engineering, Center for Developmental Biology, RIKEN Kobe, Chuo-ku, Kobe \\ 650-0047, Japan
}

\begin{abstract}
One of the central issues in developmental neurobiology is how the forebrain is organized ontogenetically. The traditional view is that the anterior neuroectoderm first develops into mesencephalic and prosencephalic vesicles; the latter vesicle subsequently develops into the diencephalon and secondary prosencephalon, of which dorsal parts protrude to generate the telencephalon. The diencephalon yields the pretectum, thalamus, and prethalamus, and the telencephalon produces the archipallium, neopallium, and ganglionic eminences. By identifying cell descendants that once expressed $E m \times 2$ with use of the Cre knock-in mutant into the $E m x 2$ locus and analyzing phenotypes of double mutants between Emx2 and Otx2/Otx1 and between Emx2 and Pax6, we propose that at the 3-6 somite stage, the anterior neuroectoderm develops into three primordia: midbrain, caudal forebrain, and rostral forebrain. The caudal forebrain primordium generates not only the pretectum, thalamus, and prethalamus but also the archipallium, cortical hem, choroid plexus, choroidal roof, and eminentia thalami. The primordium corresponds to the Emx2- or Pax6-positive region at the 3-6 somite stage that most probably does not include the future neopallium or commissural plate. $0 t x 2$ and $0 t x 1$ that are expressed in the entire future forebrain and midbrain cooperate with this Emx2 and Pax6 expression in the development of the caudal forebrain primordium; Emx2 and Pax6 functions are

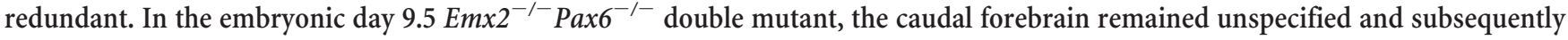
transformed into tectum in a mirror image of the endogenous one.
\end{abstract}

Key words: Emx2; Pax6; Otx2; forebrain; archipallium; diencephalon; tectum

\section{Introduction}

The rostral brain comprises a series of structures rostrocaudally and dorsoventrally. It is widely accepted that in front of the midbrain, the forebrain consists caudorostrally of the pretectum (p1), thalamus (dorsal thalamus, p2) and prethalamus (ventral thalamus, p3) (Puelles and Rubenstein, 1993, 2003). However, it is still a matter of dispute how forebrain structures in front of the prethalamus are organized; moreover, it is not yet certain how the forebrain is regionalized into these structures ontogenetically. An initial version of the prosomeric model postulated the archipal-

Received Jan. 18, 2005; revised April 3, 2005; accepted April 3, 2005.

This work was supported by a grant-in-aid for Scientific Research on Priority Areas from the Ministry of Education Culture, Sports, Science and Technology of Japan. We thank Dr. Luis Puelles for critical reading of this manuscript and Dr. S. Yonemura and N. Inoue for semithin and ultrathin analyses. We are indebted to Drs. K. Abe, A. P. McMahon, J. L. R. Rubenstein, P. Gruss, D. J. Anderson, P. Charnay, M. Taira, M. Frohman, H. Clevers, A. Joyner, D. G. Wilkinson, G. Martin, E. Lai, T. Miyamoto, and T. Ogura for providing in situ hybridization probes and to Drs. H. Hamada, V. van Heyningen, and N. Osumi and The Jackson Laboratory for providing Lefty-Cre, Sey, and ROSA26R mice. We are grateful to the Laboratory for Animal Resources and Genetic Engineering for the generation of the $E m \times 2^{+/ / r e}$ mutant and for the housing of mice.

*J.K. and Y.S. contributed equally to this work.

Correspondence should be addressed to Dr. Shinichi Aizawa, Laboratory for Vertebrate Body Plan, Center for Developmental Biology, RIKEN Kobe, 2-2-3 Minatojima Minami-machi, Chuo-ku, Kobe 650-0047, Japan. E-mail: saizawa@cdb.riken.go.jp.

DOI:10.1523/JNEUROSCI.0239-05.2005

Copyright $\odot 2005$ Society for Neuroscience $\quad$ 0270-6474/05/255097-12\$15.00/0 lium and eminentia thalami as 4 structures rostral to $\mathrm{p} 3$ prethalamus and caudal to 55 neopallium (here "caudal forebrain" is used to indicate these $\mathrm{p} 1$ to $\mathrm{p} 4$ structures). In the traditional view, however, the archipallium is a dorsomedial structure, the neopallium is a dorsolateral structure, and ganglionic eminences are ventral structures of the telencephalon rostrally to the prethalamus (here "telencephalon" is used in this sense).

The initial morphological landmark in the anterior neuroectoderm is the preotic sulcus. In the neural plate rostral to this sulcus, a series of transcriptional factors, Otx2, Gbx2, Pax2, En1, Pax6, Irx3, and Six3, are expressed in a nested pattern, initially partly overlapping each other but being distinctly segregated by the 6-8 somite stage. This, together with the overexpression/ ectopic expression studies in avian, led to a proposal that mutually inhibitory interactions among these genes determine the boundaries between each territory in the rostral brain (Kobayashi et al., 2002). The view proposes three divisions in the initial brain regionalization: forebrain rostral to zona limitans intrathalamica (ZLI), that caudal to ZLI, and midbrain. Another view in avian proposes that in the forebrain, the pretectum first differentiates and the thalamus and prethalamus are formed with the ZLI development (Larsen et al., 2001). Several mouse mutants are reported that exhibit defects in rostral brain development: Pax2/5, En2/En1, Pax6 (Sey), Six3, and Hesx1 (Stoykova et al., 1996; War- 
ren and Price, 1997; Schwarz et al., 1999; Martinez-Barbera et al., 2000; Liu and Joyner, 2001; Lagutin et al., 2003). However, the details of the defects, their processes, and the primary limits remain for future studies to synthesize ontogeny of forebrain structures.

Previously, we reported that in the Em $\times 2^{-/-} \mathrm{Ot} \times 2^{+/-}$mutant, the commissure region of the pretectum develops but the noncommissure region of the pretectum, prethalamus, and thalamus are lost (Suda et al., 2001). In contrast, the ectopic Emx2 expression over the entire forebrain and midbrain in the Otx2 locus $\left(O t \times 2^{+/ E m x 2}\right)$ is specifically incompatible with the development of the commissure region of the pretectum. Emx2 is not expressed in the pretectum or thalamus when they are formed. Moreover, the Otx2 expression is not unique to the caudal forebrain; How is the caudal forebrain specified in the Em $\times 2^{-/-}$mutant? This situation can be explained simply by postulating a third gene, $X$, the expression of which overlaps and is functionally redundant with the Emx2 expression. Here, we propose that $X$ is the Pax6 gene and that the caudal forebrain primordium spanning from the future pretectum to the archipallium is established against rostral forebrain and midbrain primordia at the 3-6 somite stage through the cooperation of Emx2 and Pax6 with Otx2 and Otx1.

\section{Materials and Methods}

Mutant mice. Emx2, Emx1 (Yoshida et al., 1997), Otx2 (Matsuo et al., 1995), and Otxl (Suda et al., 1997) mutant mice were generated as described. The sources of Sey and ROSA26R mice are as described previously (Hill et al., 1991; Soriano, 1999). Mice were housed in environmentally controlled rooms under the institute guidelines for animal and recombinant DNA experiments.
Generation of Cre knock-in mutant into Emx2 locus. To construct the targeting vector, the neomycin-resistant gene directed by the $P G K$ gene promoter and polyadenylation (polyA) signal (neo) was flanked with loxP sequences; moreover, this was conjugated to the Cre recombinase gene $(\mathrm{Cre})$ that lacks the polyA signal, generating the Cre-neo cassette. A DNA fragment encompassing $6.8 \mathrm{~kb} 5^{\prime}$ upstream to $2.3 \mathrm{~kb} 3^{\prime}$ downstream of the translation initiation site of the $E m \times 2$ gene was isolated from C57BL/6 genomic DNAs. The Cre-neo cassette was inserted into the translational initiation codon of this fragment; ATG of the Cre gene corresponds to ATG of the Emx2 gene (supplemental Fig. 2, available at www.jneurosci.org as supplemental material). The diphtheria toxin-A fragment gene, driven by the $\mathrm{MC1}$ promoter, was used for negative selection of homologous recombinants as described previously (Yagi et al., 1993b). Details of the vector construction will be provided on request. The vector was linearized with NotI digestion, homologous recombinants were isolated with TT2 embryonic stem cells, and mutant mice $\left(E m \times 2^{+/ C r e-n e o}\right)$ were generated as described previously (Yagi et al., 1993a). The mice were mated with LeftyCre mice (Yamamoto et al., 2001) to excise neo, generating $E m \times 2^{+/ C r e}$ mice.

Genotyping of mice. Genotypes of mice and embryos were determined routinely by PCR; genomic DNAs were obtained from tails or yolk sacs. The primers used to identify Emx2, Emx1, Otx2, Otx1, Pax6, and ROSA26R wild-type and mutant alleles were as described previously (Grindley et al., 1995; Matsuo et al., 1995; Suda et al., 1997; Yoshida et al., 1997; Soriano, 1999). Those primers used to detect the Cre-neo knock-in allele in the Emx2 locus were the $5^{\prime}$ primer (5'-GCCTGCTTGCCGAATATCATGGTGGAAAAT- $\left.3^{\prime}\right)$ in the neo gene and the $3^{\prime}$ primer $\left(5^{\prime}\right.$ GACTGGAATTGGCGTAGCTGAGTG-3') in the first exon of the Em $x 2$ gene; the primers used to detect the Cre knock-in allele were the $5^{\prime}$ primer (5'-AAGAAGCGAACACTTCCATGGATTGTC- $3^{\prime}$ ) in the $5^{\prime}$ untranslated region of the Emx2 gene and the $3^{\prime}$ primer (5'-CGAACATCTTCAGGTTCTGCGG- $3^{\prime}$ ) in the Cre gene.

Histochemical analysis. $\beta$-Galactosidase $(\beta \mathrm{Gal})$ staining and histolog-
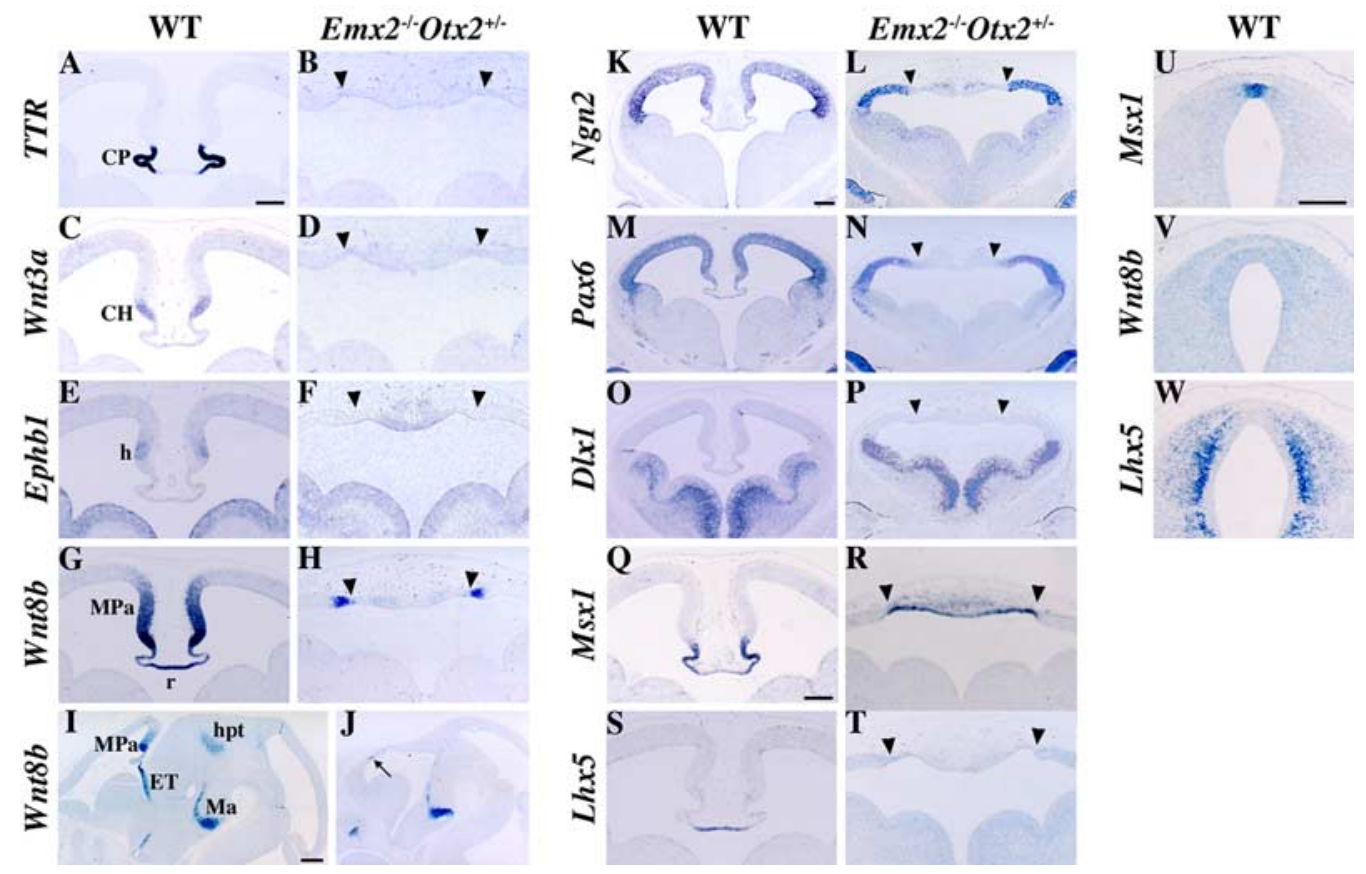

Figure 1. Marker analysis of archipallial defects in the $\mathrm{E} 12.5 \mathrm{Em} \times 2^{-/-} \mathrm{Otx} 2^{+/-}$mutant. The images give sagittal $(\boldsymbol{I}, \boldsymbol{J})$ and frontal views at the telencephalic $(\boldsymbol{A}-\boldsymbol{H}, \boldsymbol{K}-\boldsymbol{T})$ and mesencephalic $(\boldsymbol{U}-\boldsymbol{W})$ levels; the markers and genotypes of embryos examined are indicated to the left and at the top, respectively. In wild-type embryos (WT), TTR demarcates the choroid plexus (CP; $\boldsymbol{A})$, Wnt3a demarcates the cortical hem $(\mathrm{CH} ; \boldsymbol{C}$, and Ephb1 demarcates the prospective hippocampus $(h ; \boldsymbol{E})$. They are absent in the double mutant $(\boldsymbol{B}, \boldsymbol{D}, \boldsymbol{F})$. Normally, Wnt $8 b$ is expressed in the medial pallium $(\mathrm{MPa} ; G, I)$, eminentia thalami $(\mathrm{ET} ; \boldsymbol{I})$, vicinity of habenulopeduncular tract $(\mathrm{hpt} ; \boldsymbol{I})$, and mammillary region $(\mathrm{Ma} ; \boldsymbol{I})$. In the double mutant, the Wnt8b-positive mammillary region is present $(J)$ but the medial pallium is residual $(\boldsymbol{H}$, arrow in $\boldsymbol{J}) ; W n t 8 b$-positive eminentia thalami and habenulopeduncular tract vicinity are lost $(\boldsymbol{H}, \boldsymbol{J})$. The $\mathrm{Ngn2}$ - and Pax6-positive neopallium $(\boldsymbol{K}, \boldsymbol{M})$ is present laterally in the double mutant $(\boldsymbol{L}, \boldsymbol{N})$; the $D / x 1$-positive subpallium is normally found $(\mathbf{O}, \boldsymbol{P})$. In this stage of the wild-type telencephalon, the Msx 1 expression is intense in the choroid plexus and ventral cortical hem but weak in the choroidal roof $(\mathbf{Q})$; the Msx 1 expression is intense in the double mutant roof $(\boldsymbol{R})$. The wild-type choroidal roof $(\mathrm{r})$ expresses $W n t 8 b(\boldsymbol{G})$ and $L h \times 5(\boldsymbol{S})$, whereas the double mutant roof does not express either of them $(\boldsymbol{H}, \boldsymbol{T})$. Of note is that the midbrain roof expresses Msx 7 intensively $(\boldsymbol{U})$ but not $W n t 8 b(\boldsymbol{V})$ or $L$ hx 5 (W). Arrowheads in the double mutant panels indicate the medial limits of the Wnt8b-positive medial pallium that correspond to the lateral limits of the Msx1-positive roof. Scale bars, $240 \mu \mathrm{m}$. 
A

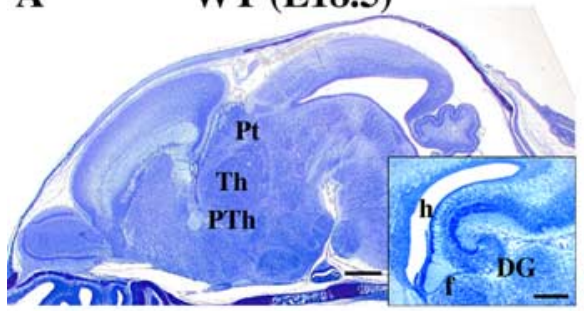

C

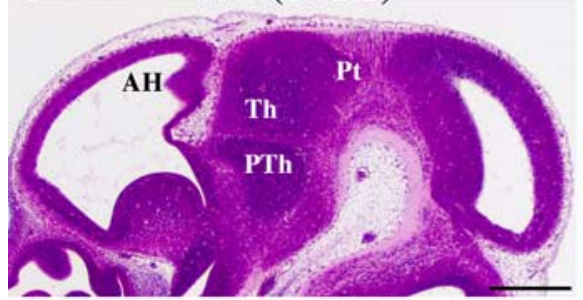

E $\quad \mathrm{Emxl}^{+}{ }^{+} \mathrm{Otx} 2^{+/-}(\mathrm{E} 12.5)$

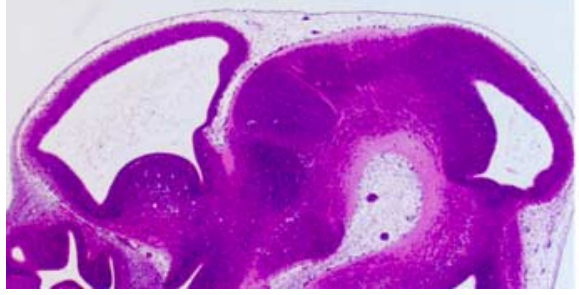

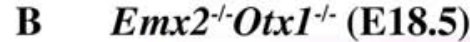

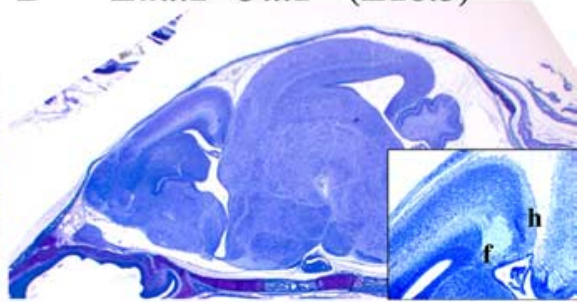

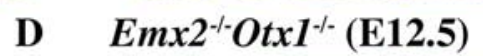

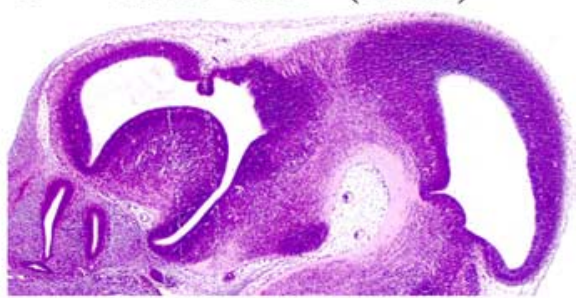

F $\quad \mathrm{Emxl}^{\circ} \mathrm{Otx}^{\circ}(\mathbf{E} 12.5)$

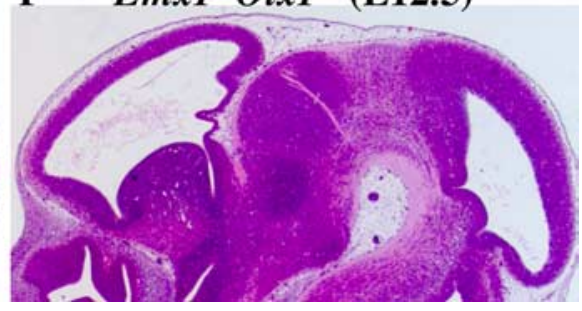

Figure 2. Emx2/0tx1,Emx1/0tx2, and Emx1/0tx1 double mutant phenotypes. Sagittal sections of E18.5 embryos stained with cresyl violet $(\boldsymbol{A}, \boldsymbol{B})$ and $\mathrm{E} 12.5$ embryos stained with hematoxylin and eosin $(\boldsymbol{C}-\boldsymbol{F})$ are shown. The insets in $\boldsymbol{A}$ and $\boldsymbol{B}$ show enlarged

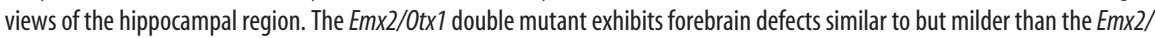
Otx2 double mutants $(\boldsymbol{B}, \boldsymbol{D})$. Defects were not apparent in either the Emx1/0tx2 $(\boldsymbol{E})$ or the $E m \times 1 / 0 t \times 1(\boldsymbol{F})$ double mutant. $A H$, Ammon's horn; DG, dentate gyrus; f, fimbria; h, hippocampus; Pt, pretectum; PTh, prethalamus; Th, thalamus. Scale bars: $A, C, 500$ $\mu \mathrm{m} ; \boldsymbol{A}$, inset, $250 \mu \mathrm{m}$.

ical analysis were performed as described previously (Suda et al., 2001; Kurokawa et al., 2004a).

RNA in situ hybridization. Section and whole-mount in situ hybridization were performed using digoxigenin probes as described previously (Wilkinson, 1993). The probes used were as follows: BF1 (Tao and Lai, 1992), Dlx1 (Bulfone et al., 1993), Dmbxl (Miyamoto et al., 2002), Ebf1 (Garel et al., 1997), Emx2 and Emx1 (Yoshida et al., 1997), En2 (Davis and Joyner, 1988), EphrinA2 (Flenniken et al., 1996), Ephb1 (IMAGE clone AA058194), Fgf8 (Crossley et al., 1996), Gbx2 (Bulfone et al., 1993), Irx1 (Bosse et al., 1997), Lhx2 (Porter et al., 1997), Lhx5 (Sheng et al., 1997), Lim1 (Fujii et al., 1994), Msx1 (Hill et al., 1989), Ngn2 (Sommer et al., 1996), Otx2 (Matsuo et al., 1995), Pax2 (Dressler et al., 1990), Pax6 (Stoykova et al., 1996), Shh (Echelard et al., 1993), Six3 (Oliver et al., 1995), Tcf4 (Korinek et al., 1998), TTR (Wakasugi et al., 1985), Wnt3a (Roelink and Nusse, 1991), Wnt7b (Parr et al., 1993), and Wnt8b (IMAGE clone AA170920).

\section{Results}

Archipallium, choroid plexus, and eminentia thalami are also lost in $E m x 2^{-/-} O t x 2^{+/-}$double mutant

Our previous study demonstrated that the prethalamus, thalamus, and anterior pretectum are lost in the Em $\times 2^{-/-}$Ot $x 2^{+/-}$ double mutant; however, the analysis was incomplete as to the defects in more anterior regions (Suda et al., 2001). The double mutant does not develop beyond embryonic day 15.5 (E15.5) (Suda et al., 2001). In this telencephalon, the neopallium was reduced with a disorganized laminar structure; the cortical plate was hardly visible. Ganglionic eminences were hyperplastic. However, these regions were present whereas neither the CA

fields, dentate gyrus, fimbria, nor choroid plexus was formed at E15.5, and Ammon's horn was not apparent at E12.5. To confirm this telencephalic phenotype, analyses were made with molecular markers. In the most medial pallium adjacent to the roof, transthiretin (TTR)-positive choroid plexus develops (Fig. $1 \mathrm{~A}$ ); it is adjacent to the Wnt3a-, Wnt5a-, and $W n t 2 b$-positive fimbria or cortical hem (Fig. 1C) (Grove et al., 1998). Ephb1 and Proxl expressions cover the hippocampal field (Fig. 1E) (data not shown), and Wnt8b and Lef1 expressions cover the entire medial pallium (Fig. 1G,I) (data not shown). Neither the TTR-, Wnt3a-, Wnt5a-, Wnt2b-, Ephb1-, nor Prox1-positive structure was apparent in the Emx2/Otx2 double mutant (Fig. $1 B, D, F)$ (data not shown). The Wnt8b and Lef1 expression was residual in the medial pallium (Fig. 1H) (data not shown), and Wnt8b-positive eminentia thalami were lost (Fig. $1 \mathrm{~J}$ ). In contrast, the Wnt8b-negative and Ngn2- and Pax6positive neopallium developed laterally; the $D l x 1$-positive subpallium was formed almost normally (Fig. $1 L, N, P$ ).

Morphologically, the midline structure between Wnt8b-positive remnants in the double mutant (the structure between two arrowheads in Fig. 1) was the roof; however, it was not the telencephalic roof. In the wild-type dorsal telencephalon, Msx 1 is intense in the choroid plexus and ventral cortical hem and weak in the roof (Fig. 1Q). The Msxl expression was intense in the double mutant roof (Fig. 1R). The wild-type choroidal roof expresses $W n t 8 b$ (Fig. $1 G$ ) and $L h x 5$ (Fig. 1S); the double mutant roof expressed neither of them (Fig. $1 H, T$ ). The midbrain roof expresses $M s x 1$ intensively (Fig. $1 U$ ), whereas it does not express Wnt8b (Fig. $1 \mathrm{~V}$ ) or Lhx5 (Fig. $1 \mathrm{~W}$ ).

Thus, we conclude that in the Em $\times 2^{-1-} \mathrm{Ot} \times 2^{+/-}$double mutant, in addition to the prethalamus, thalamus, and anterior pretectum we described previously (Suda et al., 2001), the archipallium, cortical hem, choroid plexus, choroidal roof, and eminentia thalami fail to develop. The rostral forebrain territory of ganglionic eminences, neopallium, and the Fgf8-positive commissural plate, however, develop. A question remains as to the lateral/dorsal limit of the medial pallium loss in the double mutant. As discussed below, the intensity of the Emx2 expression is discontinuous at a boundary between the archipallium and neopallium (see Fig. $3 B b$ ). The limit of the medial pallium defect probably corresponds to this boundary. Histologically, hippocampal structures were entirely absent at E15.5 (Suda et al., 2001), and Ephb1- and Prox1-positive regions were completely missing. We speculate that the $W n 8 b$ and Lef1 expressions extend into the most medial neopallium or the cingulate/retrosplenial neopallium (Shinozaki et al., 2004); the residual Wnt8b- and Lef1-positive regions in the double mutant may represent this most medial neopallium. However, no data exist that demonstrates the structures to which the dorsalmost/lateralmost aspect of the Wnt8b-and Lef1-positive regions actually correspond. 
Otx1 cooperates with $E m x 2$, but $E m x 1$ does not cooperate with Otx2 or Otx1, in forebrain development

Otx2 and Emx2 have cognates, Otx1 and Emx1, respectively. It was then examined whether these cognates also participate in forebrain development. Histologically, development of the prethalamus, thalamus, and pretectum was meager in the E18.5 and E12.5 Emx $2^{-/-}$Otx $1^{-/-}$double mutant (Fig. $2 B, D$ ). The telencephalon was smaller, but the choroid plexus developed in the double mutant. The hippocampal field developed poorly at E18.5 (Fig. 2B, inset), and at E12.5, Ammon's horn was markedly deformed (Fig. 2D). Molecular marker analyses at E12.5 with Ebf1, Lim1, Gbx2, Tcf4, Pax6, and Dlx 1 indicated that only abnormal remnants of the anterior pretectum, thalamus, and prethalamus remained in the Emx2 $2^{-/-}$Otx $1^{-/-}$mutant (supplemental Fig. 1, available at www. jneurosci.org as supplemental material). The analyses on Ephb1, Lef1, and Wnt8b expression also suggested great reduction in the medial pallium (data not shown). Thus, Emx2 cooperates not only with Otx 2 but also with Otxl for forebrain development. In contrast, defects were not apparent in the forebrain of either the Emx $1^{-/-} O t \times 2^{+/-}$or the $E m \times 1^{-/-} O t \times 1^{-/-}$mutant (Fig. 2E,F); $E m x 1$ does not cooperate with Otx2 or Otx1. This is consistent with the later onset of Emx1 expression at approximately E9.5 (Simeone et al., 1992; Yoshida et al., 1997) in a more limited region of the forebrain, the pallium.

\section{Origin of the thalamus and pretectum cells}

The Emx2 mRNA expression is not found at E9.5 in the region posterior to ZLI (Fig. 3Ac) (Simeone et al., 1992; Suda et al., 2001). At E12.5, the expression is persistent in the pallium, whereas it is faint in eminentia thalami and others (Fig. $3 A d$ ). Obviously, the Emx2 expression narrows with the forebrain development. To determine cell descendants that once expressed $E m \times 2$, mice were generated in which the Cre recombinase gene was knocked-in into the Emx2 locus (supplemental Fig. 2, available at www.jneurosci.org as supplemental material) and mated with ROSA26R mice (Soriano, 1999). The analysis has inherent problems of incomplete and ectopic Cre-mediated recombination, but the $\beta \mathrm{Gal}$ expression in embryos that harbor both Cre in the Emx2 locus and ROSA26R clearly demonstrated the cells that once expressed Emx2. At E9.5, the $\beta \mathrm{Gal}$-positive region was found in the intermediate mesoderm, eyes, nose, and
(A)

3s $5 \mathrm{~s}$ E9.5
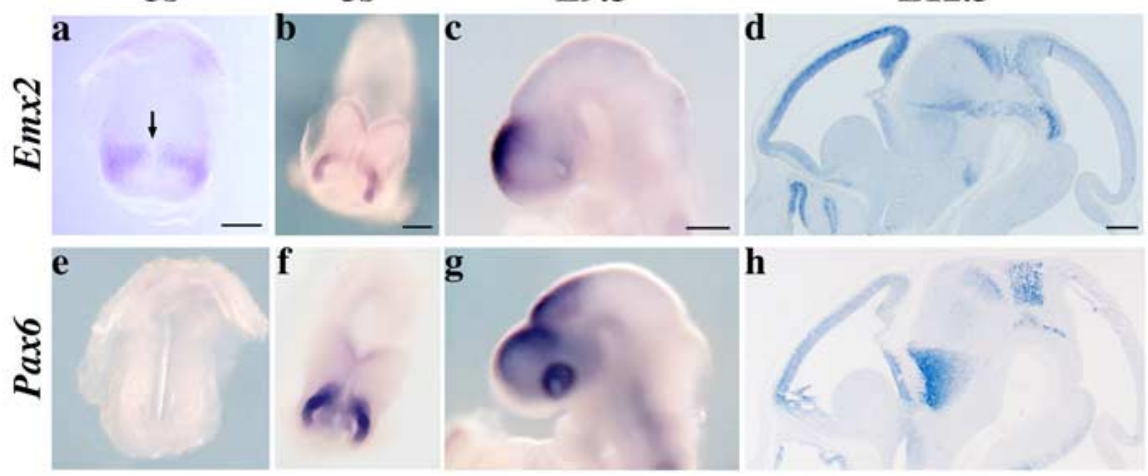

(B)
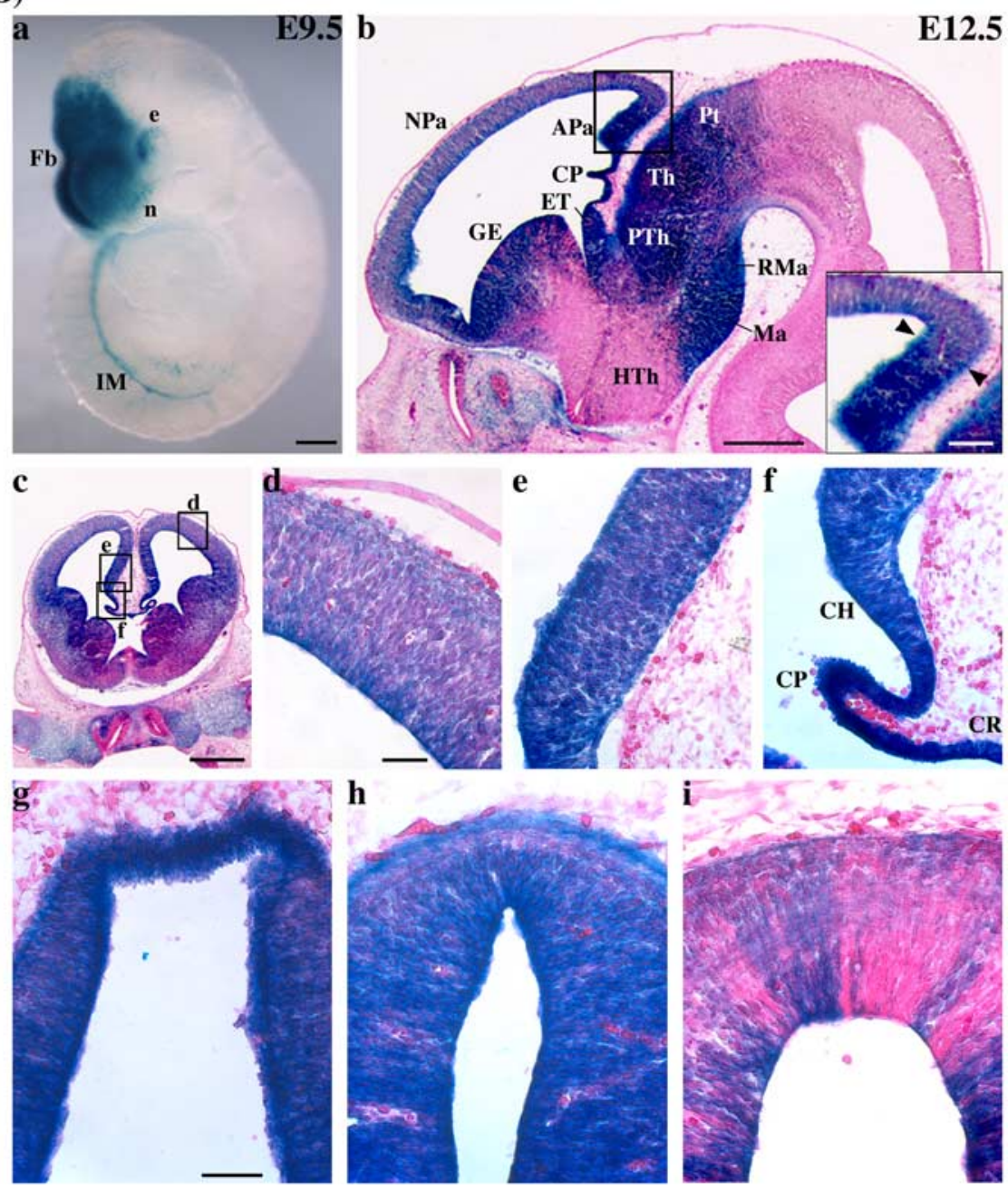

Figure 3. Analysis of cell descendants that once expressed Emx2.A,Emx2 and Pax6mRNA expression at stages indicated at the top. Anterior is at the bottom $(\boldsymbol{a}, \boldsymbol{b}, \boldsymbol{e}, \boldsymbol{f})$ and to the left $(\boldsymbol{c}, \boldsymbol{d}, \boldsymbol{g}, \boldsymbol{h})$. The arrow in $\boldsymbol{a}$ indicates the absence of the Emx2 expression in the midline or future ventral diencephalon. s, Somite stage. Scale bars: (in $\boldsymbol{a}, \boldsymbol{b}$ ) $\boldsymbol{a}, \boldsymbol{b}, \boldsymbol{e}, \boldsymbol{f}, 125 \mu \mathrm{m}$; (in $\boldsymbol{c}, \boldsymbol{d}) \boldsymbol{C}, \boldsymbol{d}, \boldsymbol{g}, \boldsymbol{h}, 250 \mu \mathrm{m} . \boldsymbol{B}$, $\beta G$ al expression in R0SA26R/Emx2 ${ }^{+/ C r e}$ embryos at E9.5 (a) and E12.5 (b-i). The targeting strategy to generate $E m \times 2^{+/ C r e}$ mice is given in supplemental Figure 2 (available at www.jneurosci.org as supplemental material). Whole-mount lateral (a), sagittal $(\boldsymbol{b})$, and frontal $(\boldsymbol{c}-\boldsymbol{i})$ views are shown. The inset in $\boldsymbol{b}$ gives the enlarged view of the pallium in the squared area; the $\beta$ Gal intensity is discontinuous at a boundary (arrowheads) between the neopallium and archipallium. The squares in c indicate the sites of the enlarged views in $\boldsymbol{d}-\boldsymbol{f}$, respectively: neopallium (d); archipallium (e); cortical hem, choroid plexus, and choroidal roof $(\boldsymbol{f})$; thalamus (g); anterior pretectum (h); posterior pretectum (i). APa, Archipallium; $\mathrm{CH}$, cortical hem; $\mathrm{CP}$, choroid plexus; $\mathrm{CR}$, choroidal roof; ET, eminentia thalami; e, eye; Fb, forebrain; GE, ganglionic eminence; HTh, hypothalamus; IM, intermediate mesoderm; Ma, mammillary region; $n$, nose; NPa, neopallium; Pt, pretectum; PTh, prethalamus; RMa, retromammillary region; Th, thalamus. Scale bars: $\boldsymbol{a}, 250 \mu \mathrm{m} ; \boldsymbol{b}, \boldsymbol{c}, 500 \mu \mathrm{m} ; \boldsymbol{b}$, inset, $125 \mu \mathrm{m}$; (in $\boldsymbol{d}, \boldsymbol{g}) \boldsymbol{d}-\boldsymbol{i}, 50 \mu \mathrm{m}$. 
WT
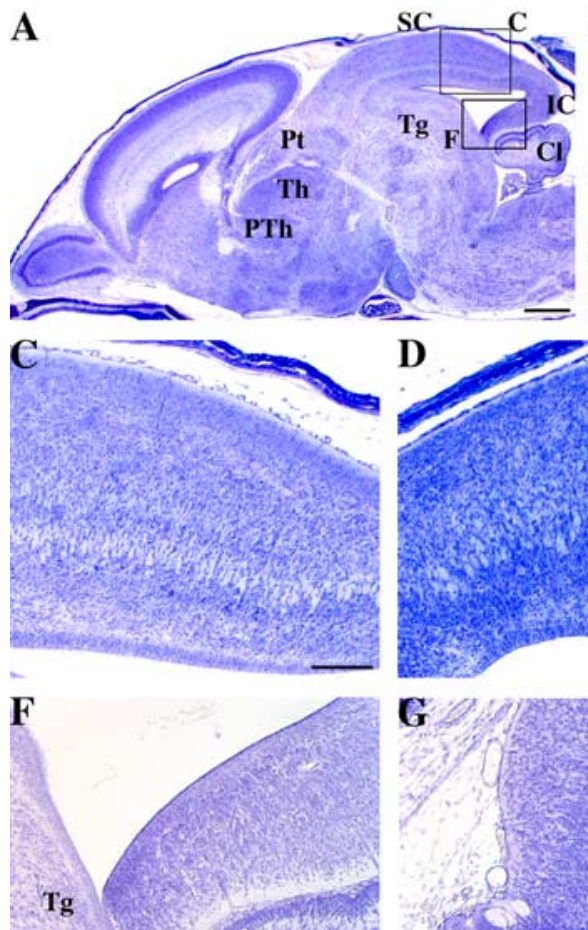

$\operatorname{Tg}$
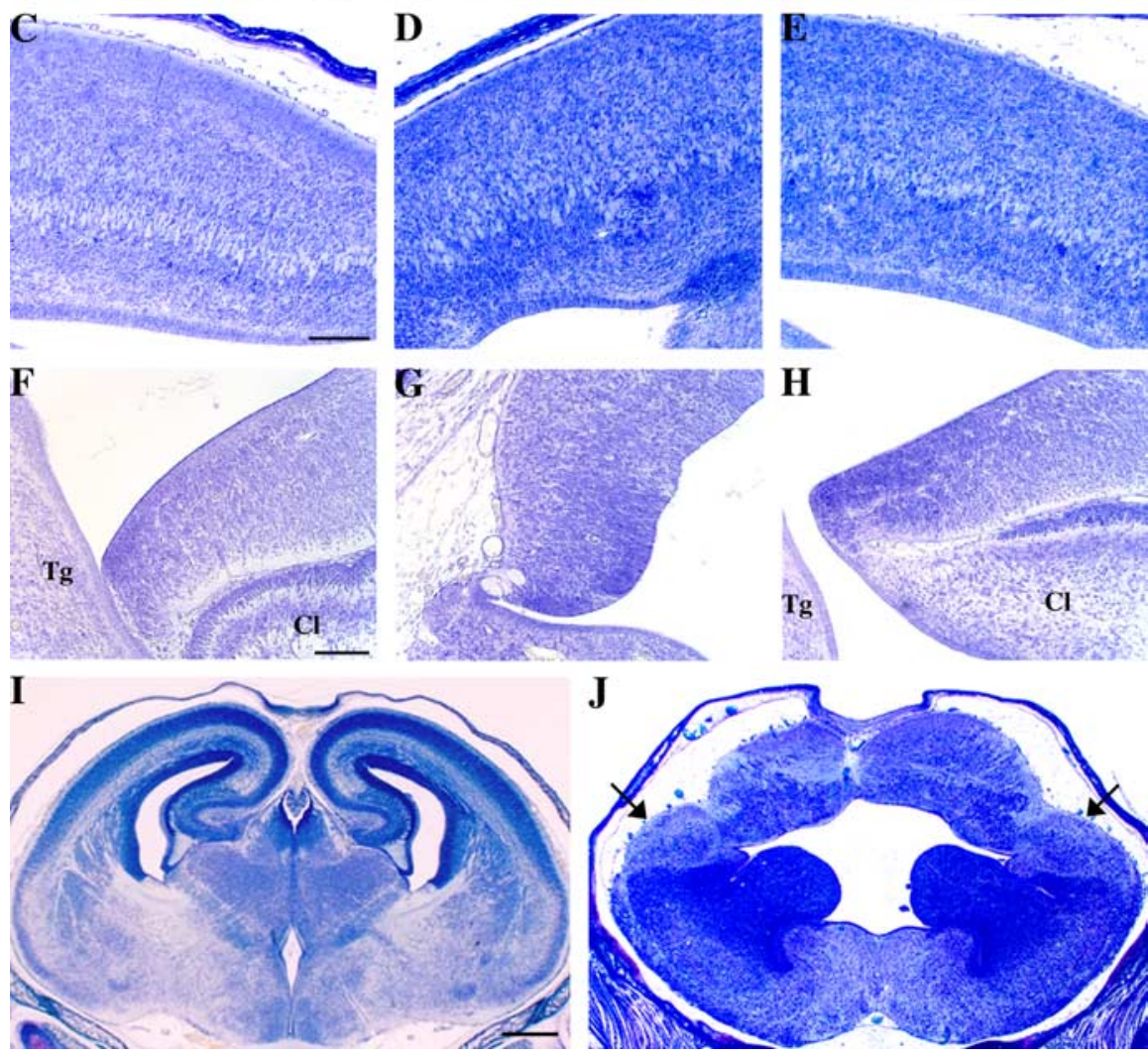

Figure 4. Tectum duplication in $E m \times 2^{-/-}$Pax $^{-/-}$double mutant. Parasagittal $(\boldsymbol{A}-\boldsymbol{H})$ and frontal $(\boldsymbol{I}, \boldsymbol{J})$ views of E18.5 wild-type $(\boldsymbol{A}, \boldsymbol{C}, \boldsymbol{F}, \boldsymbol{I})$ and double mutant $(\boldsymbol{B}, \boldsymbol{D}, \boldsymbol{E}, \boldsymbol{G}, \boldsymbol{H}, \boldsymbol{J})$ brains stained with cresyl violet are shown. $\boldsymbol{C}-\boldsymbol{H}$, Enlarged views of the sites indicated by the squares in $\boldsymbol{A}$ and $\boldsymbol{B}$. The arrows in $\boldsymbol{J}$ indicate the residual pallium. $\mathrm{Cl}$, Cerebellum; IC, inferior colliculus; $\mathrm{Pt}$, pretectum; PTh, prethalamus; SC, superior colliculus; Tg, tegmentum; Th, thalamus. Scale bars: (in $\boldsymbol{A}) \boldsymbol{A}, \boldsymbol{B}, 500 \mu \mathrm{m}$; (in $\boldsymbol{C}$ ) $\boldsymbol{C}-\boldsymbol{E}$, $125 \mu \mathrm{m}$; (in F) $\boldsymbol{F}-\boldsymbol{H}, 100 \mu \mathrm{m}$; (in I) I, J, $380 \mu \mathrm{m}$.

forebrain, as expected (Fig. $3 \mathrm{Ba}$ ); the $\beta \mathrm{Gal}$-positive region in the forebrain was, however, more caudally expanded than the endogenous Em 2 mRNA expression at this stage (Fig. 3Ac) and almost overlapped with Pax6 mRNA expression (Fig. $3 A g$ ). In the E12.5 brain, the $\beta \mathrm{Gal}$ expression was evident not only in the archipallium, eminentia thalami, and prethalamus but also in the thalamus and pretectum (Fig. $3 B b$ ).

Thus, the cell lineage analysis explains why the thalamus and anterior pretectum are lost in the Emx2/Otx2 double mutant (Suda et al., 2001). The $\beta \mathrm{Gal}$ staining was homogenously intense over the archipallium (Fig. $3 B b, B e$ ), eminentia thalami (Fig. $3 B b$ ), prethalamus (Fig. $3 B b$ ), thalamus (Fig. $3 B b, B g$ ), and anterior pretectum (Fig. $3 B b, B h$ ); the majority of cells were $\beta \mathrm{Gal}$ positive, indicating almost all of the cells in these structures once expressed Emx2. In contrast, in the posterior pretectum, the majority were instead $\beta \mathrm{Gal}$ negative (Fig. $3 \mathrm{Bb}, \mathrm{Bi}$ ). Notable was the intense $\beta \mathrm{Gal}$ expression in the most dorsomedial structures of the telencephalon (Fig. 3Bb,Bf). The Emx2 mRNA expression is never found in the ventral/medial cortical hem, choroid plexus, or choroidal roof when these structures are formed (Fig. 3Ad) (data not shown) (Tole et al., 2000; Shinozaki et al., 2004), but the cells that constitute these structures must originate almost exclusively from the cells that once expressed Emx2. In the roof, the $\beta \mathrm{Gal}$ staining extended from the pretectum to the telencephalic level (Fig. $3 B f-B i$ ); it was not found in the $F g f 8$-positive commissural plate (data not shown).

At E12.5, mammillary and retromammillary regions were also mostly composed of the cells that once expressed $E m \times 2$, and $\beta$ Gal-positive cells were evident in ganglionic eminences (Fig. $3 B b, B c)$. In contrast, the intensity of $\beta \mathrm{Gal}$ expression was apparently low in the lateral pallium (neopallium) (Fig. $3 B b, B d$ ). However, this could not be explained simply by the presence of $\beta$ Gal-negative cells; the staining intensity is influenced by cellular morphology and orientation. Of note is that the $\beta \mathrm{Gal}$ staining in the pallium was not graded; the intensity was discontinuous at a boundary between the neopallium and archipallium (Fig. 3Bb). The lineage analysis also indicates that Emx2-positive cells do not contribute posteriorly to the midbrain or anteroventrally to the hypothalamus. In addition, the influx of the cells from these regions to the Emx2positive region is also minimal, if any, consistent with the cell lineage analysis with vital dye (Inoue et al., 2000).

\section{Mirror image duplication of tectum in Emx2/Pax6 double mutant}

The E18.5 Emx2 $2^{-/-}$Pax6 $^{-/-}$double mutant phenotype was unexpected and striking. The structure dorsally developing in the double mutant, in which forebrain structures develop in wild-type embryos, was obviously histologically the tectum. Furthermore, it developed in a mirror image toward the normal one. Normally, the tectum displays a distinct rostrocaudal gradient of cytoarchitectonic maturation (Fig. $4 A$ ); rostrally superior colliculus and caudally inferior colliculus are formed. The duplicated tectum displayed the rostrocaudally opposite cytoarchitecture (Fig. $4 B-H$ ). Duplication of the cerebellum did not occur. The pallium was reduced greatly; it was lost in the medial portion (Fig. 4I,J). Ganglionic eminences were present and rather hyperplastic (Fig. $4 A, B, I, J$ ); the duplication of the tegmentum was not apparent.

Normally, En2 is expressed in the posterior midbrain at E15.5 (Fig. 5A) (Davis and Joyner, 1988); in the double mutant, an En2-positive structure was also present in the most anterior part of the "duplicated tectum" (Fig. 5B). EphrinA2 is also expressed in the caudal part of the normal midbrain (Fig. 5C) (Flenniken et al., 1996), and the duplicated tectum expressed EphrinA2 (Fig. $5 D)$. Thus, the mirror image nature of the tectum duplication was confirmed molecularly. 
At E15.5, the duplicated tectum was less pronounced than at E18.5, and at E12.5, it was even less distinct (Fig. $6 B$ ). The ectopic En 2 and EphrinA2 expressions were, however, present in the E12.5 Emx2/ Pax6 double mutant (Fig. $5 F, H$ ). The $F g f 8$ expression in the isthmus was unaffected. However, that in the commissural plate was caudally expanded by the $E m \times 2^{-1-}$ single mutation (Fig. 5O) (FukuchiShimogori and Grove, 2003; Shinozaki et al., 2004); the expansion was more marked in the Emx2 $2^{-1-} \mathrm{Pax6}^{-/-}$double mutant (Fig. 5N). Consequently, the expression fused to the Fgf8 expression in the roof of the prethalamus. At E12.5, the ectopic En2 and EphrinA2 expressions (Fig. 5F,H) were juxtaposed to this $F g f 8$ expression (Fig. 5J). At E10.5, no ectopic En2 expression was apparent (Fig. 5L).

\section{Emx2 cooperates with Pax6 in forebrain development}

In E12.5 Emx2/Pax6 double mutants, histologically an amorphous structure was present at the place where normally the thalamus/pretectum develops (Fig. $6 B$, arrow); otherwise, diencephalic structures were not apparent, and Ammon's horn also did not develop. In the $P a x 6^{-/-}$single mutant, diencephalic structures are poor but present; Ammon's horn is also apparent (supplemental Fig. 3, available at www. jneurosci.org as supplemental material) (Stoykova et al., 1996; Warren and Price, 1997). In the Sey diencephalon, although reduced, the Pax6- and Dlx 1 -positive prethalamus, Gbx2- and Tcf4-positive thalamus, and Tcf4- and Ebf1-positive pretectum are present (supplemental Fig. 3, available at www.jneurosci.org as supplemental material) (Stoykova et al., 1996). The Ebf1-negative and Pax6-/Lim1positive commissure region of the pretectum scarcely exists. Thus, Pax6 was previously concluded to function in a fine-tuning aspect of diencephalon development by regulating cell growth, but not in determination of its territory (Stoykova et al., 1996; Warren and Price, 1997). In contrast, neither the Pax6-/Dlx1-/Lim1-positive prethalamus (Fig. 6D,F,N), Gbx2-/Tcf4-positive thalamus (Fig. $6 H, J$ ), Ebfl-positive noncommissure region of the pretectum (Fig. $6 L$ ), nor Lim1-positive commissure region of the pretectum (Fig. $6 N$ ) was apparent at all in the $E m x 2^{-/-} \mathrm{Pax}^{-/-}$double mutant. The Dlx1-negative supraopto-paraventricular area was also lost (Fig. $6 F)$. The amorphous structure did not express any of the diencephalic markers and was surrounded by the Tcf4 expression (Fig. 6J); the structure might correspond to the most rostral midbrain structure, the griseum tectalis.

The Shh expression demarcates the presumptive ZLI that terminates dorsally in the Fgf8-positive prethalamus roof; this Shh $K-0,250 \mu \mathrm{m}$.
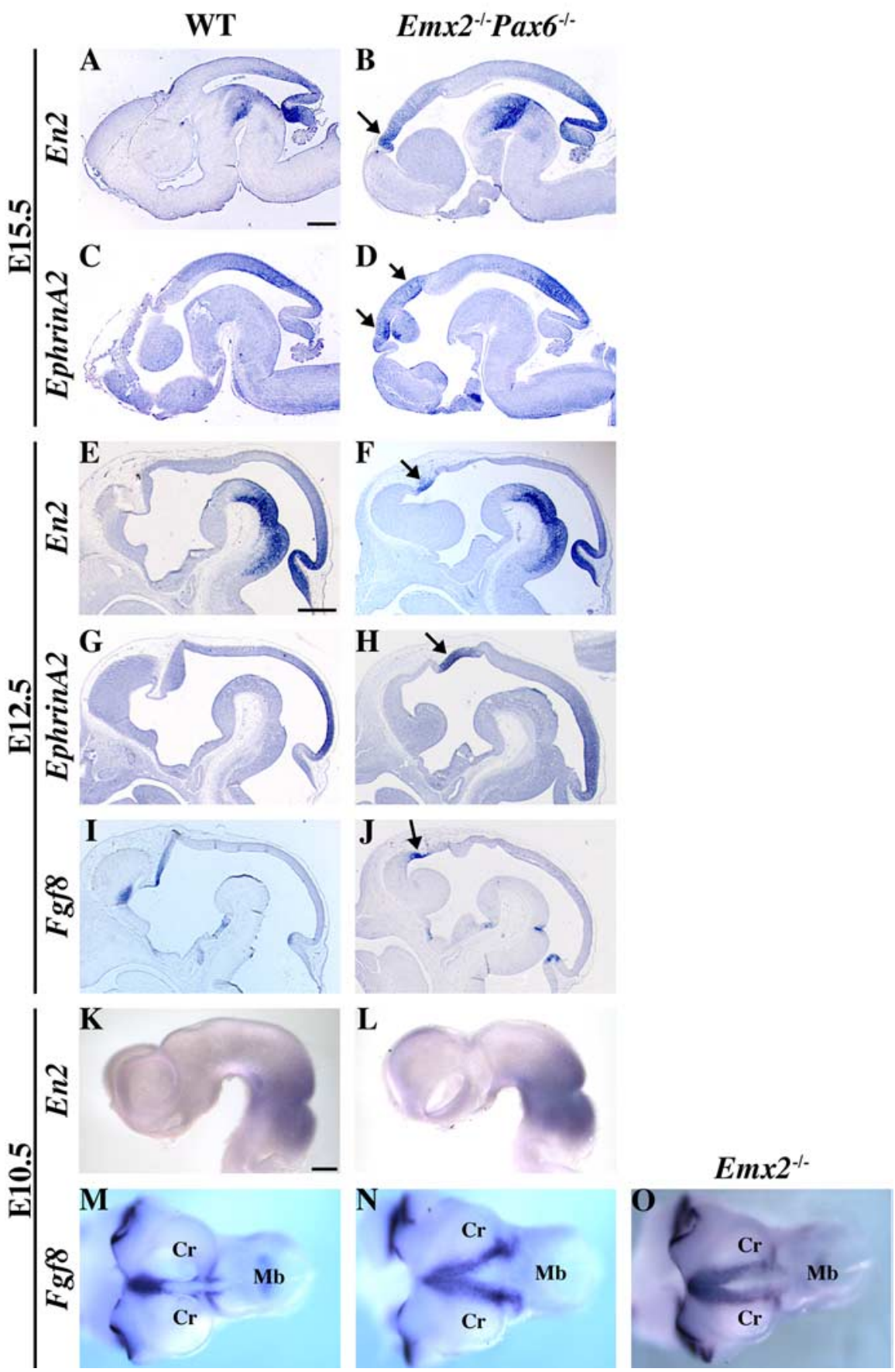

Figure 5. Marker analysis of tectum duplication in $E m \times 2^{-1-} P a \times 6^{-/-}$double mutant. En2 expression $(\boldsymbol{A}, \boldsymbol{B}, \boldsymbol{E}, \boldsymbol{F}, \boldsymbol{K}, \boldsymbol{L})$, EphrinA2 expression $(\boldsymbol{C}, \boldsymbol{D}, \mathbf{G}, \boldsymbol{H})$, and Fgf8 expression $(\boldsymbol{I}, \boldsymbol{J}, \boldsymbol{M}-\mathbf{0})$ at E15.5 (A-D), E12.5 (E-J), and E10.5 $(\boldsymbol{K}-\mathbf{O})$, respectively, in embryos of the genotype indicated at the top are shown. Mid-sagittal $(\boldsymbol{A}-\boldsymbol{J})$, whole-mount lateral $(\boldsymbol{K}, \boldsymbol{L})$, and whole-mount dorsal $(\boldsymbol{M}-\mathbf{0})$ views are shown. The arrows indicate ectopic $E n 2(\boldsymbol{B}, \boldsymbol{F})$, ectopic EphrinA2 $(\boldsymbol{D}, \boldsymbol{H})$, and Fgf8 expression rostrally juxtaposed to the ectopic En2 and EphrinA2 expression (J), respectively. (Cr, Cerebrum; Mb, midbrain. Scale bars: (in $\boldsymbol{A}, \boldsymbol{E}) \boldsymbol{A}-\boldsymbol{J}, 500 \mu \mathrm{m}$; (in $\boldsymbol{K}$ )

expression was present in the double mutant (Fig. 6P), although morphologically, ZLI was never formed. Thus, the mechanism that initiates the Shh expression is independent of forebrain development under Emx2 and Pax6. The ectopic En2 and EphrinA2 expressions (Fig. $5 F, H$ ) juxtaposed posteriorly to the dorsal end of this Shh-positive stripe, suggesting that structures rostral to the stripe are not involved in the duplication. The prethalamic region between this Shh stripe and the BF1-positive cerebrum (Fig. 6O, arrowhead) was absent in the Em $\times 2 / \mathrm{Pax} 6$ double mutant at E12.5 

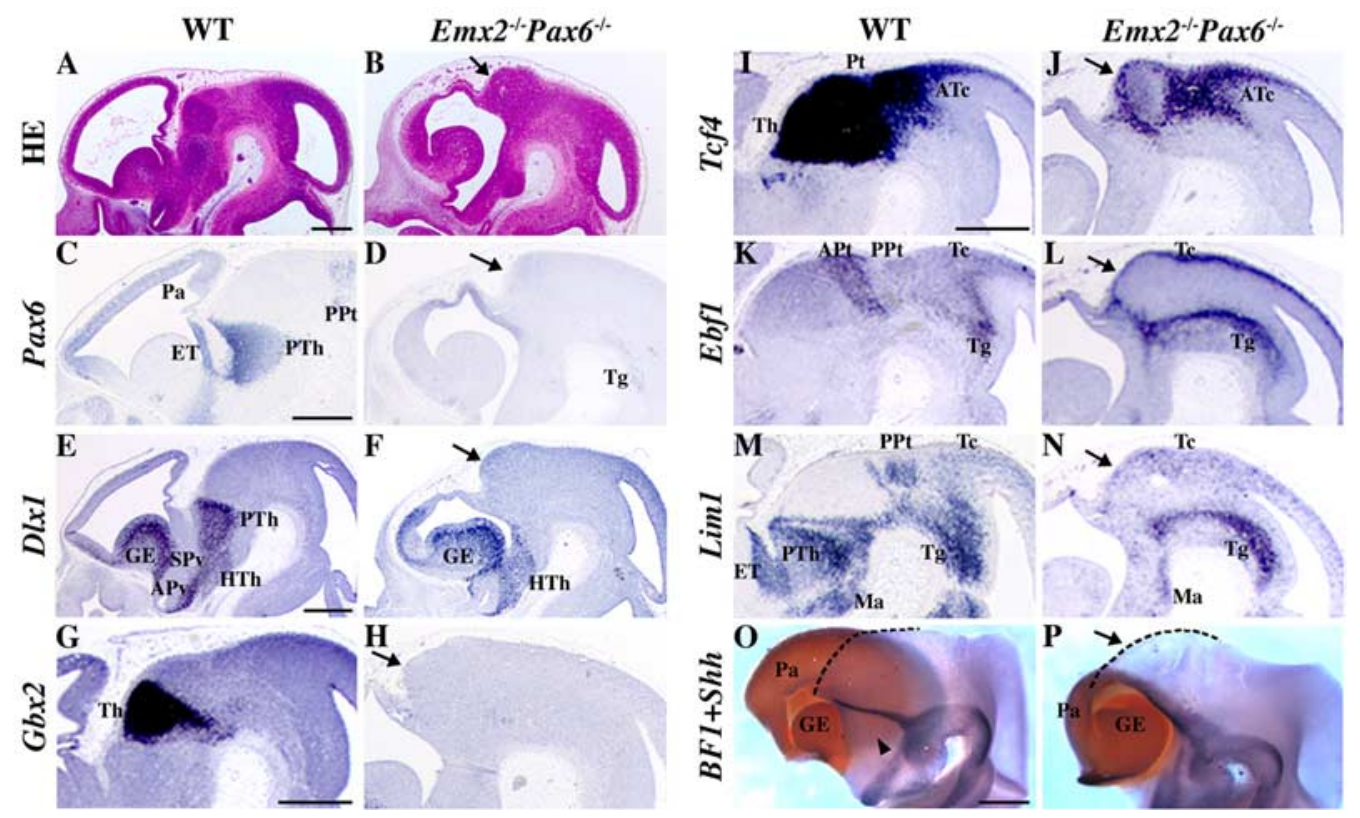

Figure 6. Marker analysis of $E m \times 2^{-/-}$Pax $6^{-/-}$double mutant defects in the $E 12.5$ diencephalon. $\boldsymbol{A}-\boldsymbol{N}$ show parasagittal views. $\boldsymbol{A}, \boldsymbol{B}$, Histological sections stained with hematoxylin and eosin. $\boldsymbol{C}-\boldsymbol{N}$, The expression of each marker is indicated to the left in embryos of the genotype indicated at the top. $\mathbf{O}$ and $\boldsymbol{P}$ show the medial views of hemisected brains, with the BF1 expression in the ganglionic eminences and pallium in orange and the Shh expression in dark blue; dotted lines contour the dorsal limits of diencephalon. The arrows in the double mutant panels indicate the ectopic structure that does not express any of the diencephalic markers indicated. The arrowhead in $\mathbf{0}$ indicates the prethalamic region that is absent in the Emx2/Pax6 double mutant $(\boldsymbol{P})$. In the Pax6 single mutant, the Pax6-, Lim 1-, and Wnt8b-positive eminentia thalami, the Pax6-, Dlx1-, and Lim1-positive prethalamus, the Gbx2-and Tcf4-positive thalamus, and the Ebf1- and Tcf4-positive anterior pretectum are reduced but present; the Pax6- and Lim 1-positive posterior pretectum scarcely exists (supplemental Fig. 3, available at www.jneurosci.org as supplemental material) (Stoykova et al.,

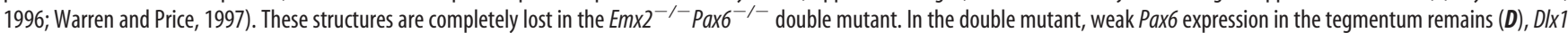
expression in the ganglionic eminences and hypothalamus is retained $(\boldsymbol{F})$, the $D / x 7$-negative anterior periventricular area develops, but the supraopto-paraventricular area is lost $(\boldsymbol{F})$, and $I c f 4$ expression is kept in the anterior tectum and surrounds the ectopic structure that does not express any diencephalic markers $(\boldsymbol{J})$. Normally Ebf1 expression is found in the anterior pretectum, tectum, and tegmentum but not in the posterior pretectum $(\boldsymbol{K})$. In the double mutant, the expression in the anterior pretectum is lost and that in the tectum and tegmentum is expanded rostrally $(\boldsymbol{L})$. Lim 1 expression in the mammillary region is retained, and the expression in the tectum and tegmentum is expanded rostrally $(\boldsymbol{N})$. The BF1-positive pallium is also greatly reduced in the double mutant, but the ganglionic eminences are hyperplastic $(\boldsymbol{P})$. The $E m \times 1^{-1-} E m \times 2^{-1-} \mathrm{Pax}^{-1-}$ triple mutant phenotype was the same as the double mutant one. See supplemental Figure 3 (available at www.jneurosci.org as supplemental material) for comparison of these marker phenotypes among the single, double, and triple mutants. APt, Anterior pretectum; $\mathrm{APv}$, anterior periventricular area; ATc, anterior tectum; ET, eminentia thalami; GE, ganglionic eminences; $H T$ Th, hypothalamus; Ma, mammillary region; Pa, pallium; PPt, posterior pretectum; Pt, pretectum; PTh, prethalamus; $\mathrm{SPv}$, supraopto-paraventricular area; $\mathrm{Tc}$, tectum; Tg, tegmentum; Th, thalamus. Scale bars, $500 \mu \mathrm{m}$.

(Fig. 6P), consistent with the lack of the Pax6-/Dlx1-/Lim1positive prethalamus; it is present in the Pax6 single mutant (supplemental Fig. 3, available at www.jneurosci.org as supplemental material). The BF1-positive pallium was also greatly reduced in the double mutant at this stage. In these diencephalic phenotypes, the Em $x 1^{-/-} \mathrm{Pax}^{-1-}$ double mutant was the same as the $\mathrm{Pax}^{-1-}$ single mutant (data not shown), and the $E m \times 1^{-1-} E m \times 2^{-1-} \mathrm{Pax}^{-1-}$ triple mutant was the same as the $E m \times 2^{-1-} \mathrm{Pax}^{-1-}$ double mutant (supplemental Fig. 3, available at www.jneurosci.org as supplemental material).

In the telencephalon, morphologically the choroid plexus was never apparent, and TTR expression was not observed in lateral ventricles of the Emx2/Pax6 double mutant (Fig. 7B). The $W n t 3 a-$, Wnt5a-, and Wnt2b-positive cortical hem did not exist (Fig. 7D) (data not shown), and the Ephb1- and Proxl-positive hippocampal field was never found (Fig. $7 F$ ) (data not shown). The Wnt8b- and Lef1-positive medial pallium was residual (Fig. $7 H$ ) (data not shown). These structures were also affected but clearly present in $\mathrm{Pax}^{-1-}$ (supplemental Fig. $4 \mathrm{Ab}-\mathrm{Db}$, available at www.jneurosci.org as supplemental material) (data not shown) and

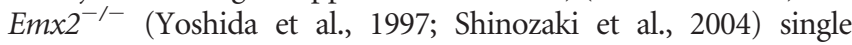
mutants.

The Dlx 1 expression extends dorsally into the neopallial region in the Pax6 $6^{-1}$ single mutant (supplemental Fig. 4 Eb, available at www.jneurosci.org as supplemental material) (Stoykova et al., 2000) and even more in the double mutant (Fig. 7N) (Mu- zio et al., 2002). Consequently, the Pax6-, Emx1-, and Ngn2positive neopallium was greatly reduced but present at E12.5 (Fig. $7 P, R, T)$; the expression of these markers overlapped ventrally with $D l x 1$ expression (the dorsal limits of the $D l x 1$ expression are indicated by arrows in the double mutant panels of Fig. 7). Moreover, the pallium medially expressed roof markers $L h \times 5, M s x 1$, and Otx2 (Fig. 7J,L) (data not shown; see Discussion) (Muzio et al., 2002); apparently the Emx2/Pax6 double mutant neopallium was incorrectly specified at E12.5. The entire pallium was, however, positive to $L h \times 2$ and $B F 1$ that are never found in the cortical hem (Fig. 7U,V) (Muzio et al., 2002) (data not shown).

The Emx2/Pax6 double mutant roof at the telencephalic level (the medial part between the arrowheads in Fig. 7) did not express choroidal roof markers: neither Wnt8b nor Lhx5 (Fig, $7 \mathrm{H}, J$ ). Instead, the Msxl expression was intense (Fig. $7 L$ ). This was also the case in the $\mathrm{Em} \times 2^{-/-} \mathrm{Ot} \times 2^{+/-}$double mutant roof at the telencephalic level (Fig. 1). In these telencephalic phenotypes, the $\mathrm{Em}_{x 1^{-\prime-} \mathrm{Pax6}^{-/-} \text {double mutant was the same as the Pax6 }}{ }^{-1-}$ single mutant, and the $E m x 1^{-1-} E m x 2^{-1-} \mathrm{Pax}^{-1-}$ triple mutant was the same as the $E m \times 2^{-1-} \mathrm{Pax}^{-1-}$ double mutant (supplemental Fig. 4, available at www.jneurosci.org as supplemental material).

\section{Onset of Emx2 $2^{-/-} \mathrm{Pax6}^{-/-}$defects}

At E10.5, the En2 expression in the caudal midbrain is somewhat expanded, and the En2-negative rostral brain is reduced in the 
Em $\times 2^{-/-} \mathrm{Pax}^{-/-}$double mutant (Fig. $5 L)$. The Shh-positive ZLI was also present at this stage (Fig. 8Ab). Of note is that at this stage a region was present between the Shh-positive stripe and BF1-positive cerebral hemispheres that corresponds to prethalamus and eminentia thalami in wildtype embryos (Fig. $8 \mathrm{Ab}$, arrows); it was not apparent at E12.5 (Fig. $6 P$ ). At this stage, $B F 1$-positive cerebral hemispheres were almost normal rostrally but somewhat reduced caudally. Pax 6 and $D l x 1$ expressions were more properly segregated into the pallium and subpallium, respectively, at E10.5 than at E12.5 (data not shown) (Muzio et al., 2002).

At E9.5, the Fgf8 expression in the isthmic region was normally found in the Emx2/Pax6 double mutant (Fig. $8 A c, A d$ ); however, the En2 expression was somewhat expanded, and the En2-negative rostral brain was slightly reduced (Fig. $8 A e, A f)$. In wild-type embryos, $D m b x 1$ is expressed in the mesencephalon and a part of the caudal diencephalon (Fig. $8 \mathrm{Ag}$ ); the $D m b \times 1$-positive region was slightly enlarged, and the BF1- and Dmbx1-negative presumptive anterior diencephalon was reduced, but obviously present, in the Emx2/Pax6 double mutant (Fig. 8Ah). $B F 1$-positive cerebral hemispheres were somewhat reduced. E9.5 is the stage when several markers start to be expressed in the diencephalic region and subregionalization occurs at this region. One such marker is $T c f 4$, which marks the future thalamus and pretectum (Fig. 8Ai); the Tcf4 expression was never observed in the Em $\times 2^{-1-} \mathrm{Pax6}^{-1-}$ double mutant (Fig. $8 \mathrm{Aj})$. Another marker examined is $\mathrm{Wnt7} \mathrm{b}$ that normally marks the future archipallium, eminentia thalami, prethalamus, and a part of the thalamus (Fig. $8 A k$ ); the $W n t 7 b$ expression was also not found in the double mutant (Fig. $8 \mathrm{Al}$ ).

Finally, the analysis was conducted at the 6 somite stage for the initial defects. The anterior neuroectoderm expresses Otx2 in the region that corresponds to the future forebrain and midbrain (Fig. $8 \mathrm{Ba}$ ), Six 3 in the most anterior region (Fig. $8 \mathrm{Bc}$ ), and $\operatorname{Ir} x 1$ complementarily in the caudal aspect of the Otx2-positive neuroectoderm (Fig. $8 \mathrm{Be}$ ). Pax6 is expressed in the caudal forebrain primordium (Fig. $8 \mathrm{Bg}$ ), and $\mathrm{Pax} 2$ is expressed in the midbrain and eye primordium (Fig. $8 \mathrm{Bi}$ ). No changes were apparent in any area positive to these markers in the Em $\times 2 / \mathrm{Pax} 6$ double mutant (Fig. $8 B b, B d, B f, B h, B j$ ). Thus, the prospective caudal forebrain region must be almost normally present in the $\mathrm{Em}_{x} 2^{-1-} \mathrm{Pax}^{-/-}$double mutant at the 6 somite stage.

\section{Discussion}

\section{Otx2/Otx1/Emx2/Pax6 and caudal forebrain}

Previously, we have identified the enhancer responsible for the Otx2 expression in the anterior neuroectoderm (AN enhancer) and reported that the $E m \times 2^{-/-} O t \times 2^{\triangle A N / \Delta A N}$ mutant that specifically lacks the $O t x 2$ expression under this enhancer exhibits the same
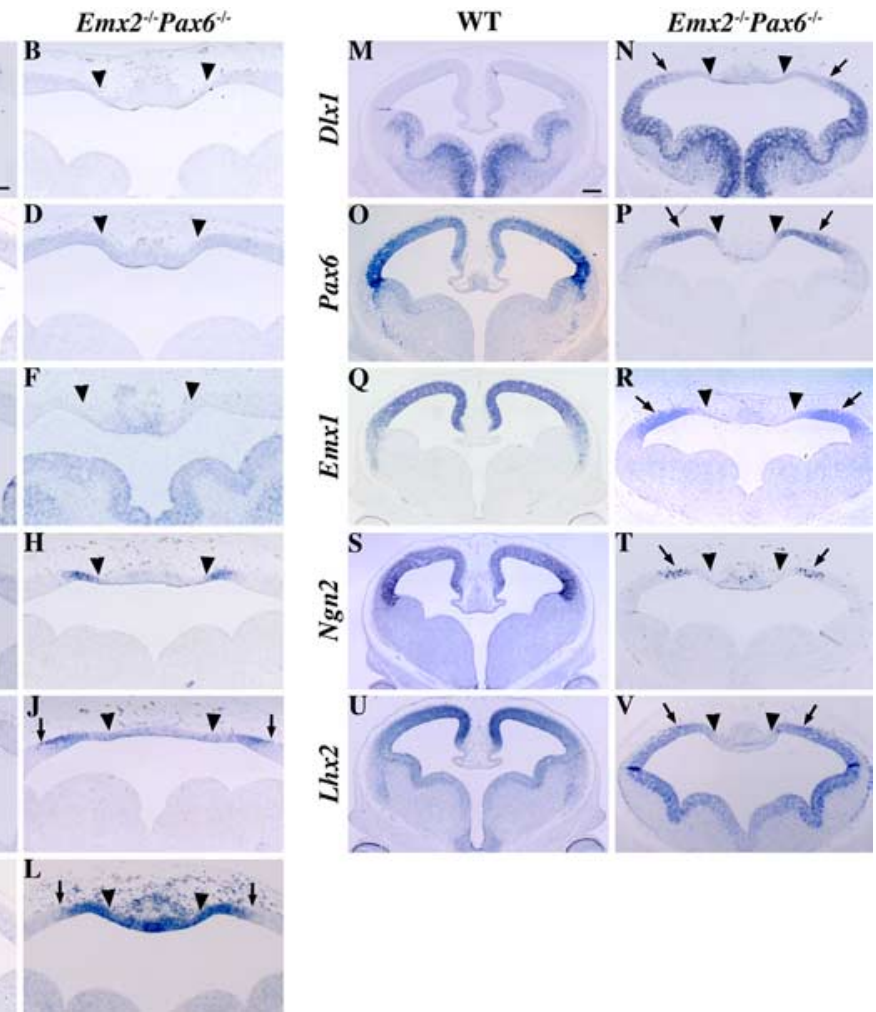

Figure 7. Marker analysis of $E m \times 2^{-/-} \mathrm{Pax}^{-/-}$double mutant defects in $\mathrm{E} 12.5$ telencephalon. The images are frontal views of the expression of each marker indicated in embryos of the genotype shown at the top. $\boldsymbol{A}-\boldsymbol{L}$ focus on the dorsomedial telencephalon, and $\boldsymbol{M}-\boldsymbol{V}$ cover the entire telencephalon. In the double mutant panels, arrows indicate the dorsal limit of the $D / x$ I

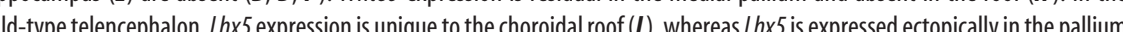
and not in the roof of the double mutant $(\boldsymbol{J})$. In the double mutant, the Msx1 expression is intense in the roof and extends laterally $-0 t \times 2^{+/-} \operatorname{roof}$ (Fig. 1). See supplemental Figure 4 (available at www.jneurosci.org as supplemental material) for comparison of these marker phenotypes among the single, double, and triple mutants. Scale bars, $240 \mu \mathrm{m}$.

defect in caudal forebrain development (Kurokawa et al., 2004a). The Emx2 expression occurs around the 3 somite stage, and the AN enhancer activity is lost beyond the 6 somite stage. This indicates that the defect occurs around the 3-6 somite stage. The Cre knock-in mutant into the Emx2 locus demonstrated that the Emx2 and Pax6 expressions initially mainly overlap and that the double mutant defects may correspond to these Emx2 and Pax6 expressions at the 3-6 somite stage. We propose that in the anterior neuroectoderm maintained by the $O t \times 2$ expression under the AN enhancer (Kurokawa et al., 2004a), Emx2 and Pax6 establish the caudal forebrain primordium in cooperation with Otx2 and Otx1 at the 3-6 somite stage (Fig. 9). In this establishment, the Emx2 and Pax6 functions are redundant, as suggested by their single mutant phenotype; in the absence of both genes, the caudal forebrain remains unspecified even at E9.5. The caudal forebrain primordium comprises not only the future pretectum, thalamus, and prethalamus but also the eminentia thalami, archipallium, cortical hem, and choroid plexus. The choroid plexus is inherently associated with the choroidal roof; both choroid plexus cells and choroidal roof cells originated from the Emx2-positive region. Coincidentally, the marker analysis indicated that the cho-

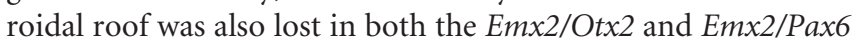


(A)
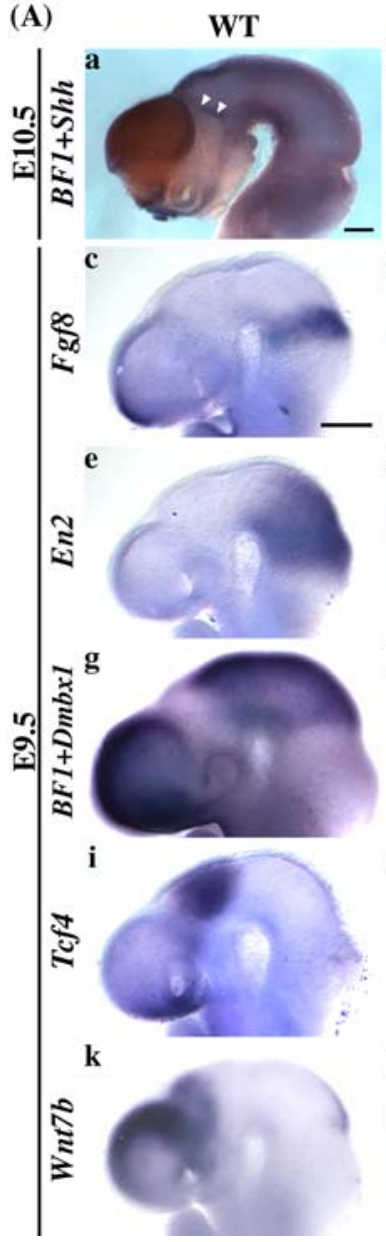
$(\boldsymbol{A} \boldsymbol{c}-\boldsymbol{A} \boldsymbol{I})$ and the 6 somite stage $(\boldsymbol{B} \boldsymbol{a}-\boldsymbol{B} \boldsymbol{j})$ are shown. All images are lateral views; anterior is to the left. The arrows in $\boldsymbol{A} \boldsymbol{b}$ indicate a region between $B F 1$-positive cerebral hemispheres (orange) and the Shh-positive stripe (dark blue); the white arrowheads in $A a$ and $\boldsymbol{A} \boldsymbol{b}$ indicate the stripe. The arrow in $\boldsymbol{A} \boldsymbol{h}$ indicates the $B F 1$ - and Dmbx1-negative diencephalic region. The asterisks in $\boldsymbol{A}$ indicate optic vesicles that are not converted into the optic cup by the Pax6 mutation (Grindley et al., 1995). The arrows in Biand Bjindicate the expression in the eyes. Scale bars, $250 \mu \mathrm{m}$.

double mutants. We assume that their roofs at the telencephalic level are the midbrain roofs. In contrast, not only the midbrain but also the ganglionic eminences, neopallium, and commissural plate were formed in both Emx2/Otx2 and Emx2/Pax6 double mutants. Defects were also not apparent in ventral structures of the forebrain.

We previously reported the loss of the archipallium, cortical hem, and choroid plexus but not the thalamic structures in the Emx1/2 double mutant (Shinozaki et al., 2004). It occurs around E9.5 when the neural tube closes at the forebrain level and when the Emxl expression takes place. In contrast, the loss of the archipallium together with thalamic structures in Emx2/Otx and Emx2/Pax6 double mutants is an event at the 3-6 somite stage. In the Emx1/2 double mutant, the archipallium is transformed into the choroidal roof and the roof is expanded; we consider that this is a defect in the later dorso(roof)/ventral(alar) patterning within the $\mathrm{p} 4$ prosomere.

\section{Emx2/Pax6 functions in the neopallium}

Em $\times 2$ and Pax6 are also expressed in the neopallium, and at late stages of gestation, the neopallium was abortive in both $E m \times 2^{-1-} \mathrm{Otx2^{+/- }}$ and $E m \times 2^{-1-} \mathrm{Pax6}^{-/-}$double mutants (Suda et al., 2001) (Fig. 4 J). One might propose that the telencephalic defects are graded, the is also not expressed in the future ventral part (midline) of the caudal forebrain or prospective region of ganglionic eminences (Fig. 3Aa). Enhancers of the later $E m \times 2$ expression in these regions are also different from the early enhancer (Theil et al., 2002; our unpublished result); among once Emx2-positive regions, Emx $2^{-1-} \mathrm{Ot} \times 2^{+/-}$and $E m \times 2^{-1-} \mathrm{Pax}^{-1-}$ double mutants developed the neopallium, ganglionic eminences, and ventral diencephalon.

The Emx2/Pax6 double mutant phenotype in the telencephalon was also analyzed by Muzio et al. (2002). We agree with their interpretation in their major issue that the neopallial territory is once formed but later respecified into a subpallial character; at E12.5, the pallium is on the way to respecification. However, Muzio et al. (2002) did not consider that the Emx2/Pax6 double mutant defect is principally the defect in the initial brain regionalization at the 3-6 somite stage and neglected the ectopic duplication of the tectum, where normally caudal forebrain is formed. The discrepancy between our view and theirs centers on the cortical hem development. By the Msx1, Otx2, and Id 3 expression, they propose that the cortical hem fate also spread into the pallial field; Emx2 was believed by them to cooperate with a low level of Pax6 dorsomedially to protect the pallium against the cortical hem fate. We do not agree with this view. The cortical hem is rather reduced in the Emx2 single mutant and lost in the Emx1/2 
(A) -2 somite: $O t x 2$ under AN enhancer

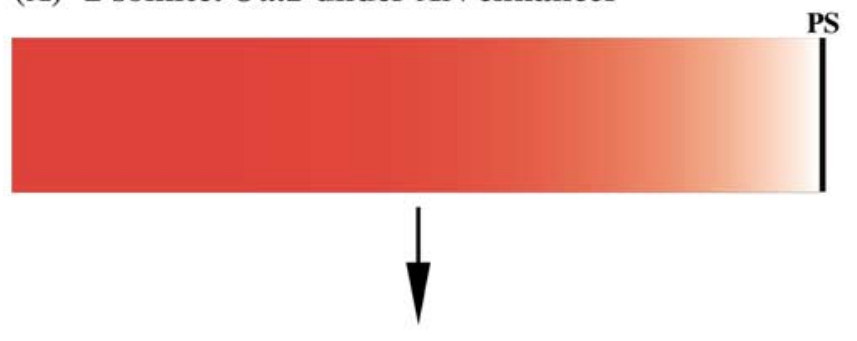

(B) 3-6 somite: $O t x 2+O t x 1$

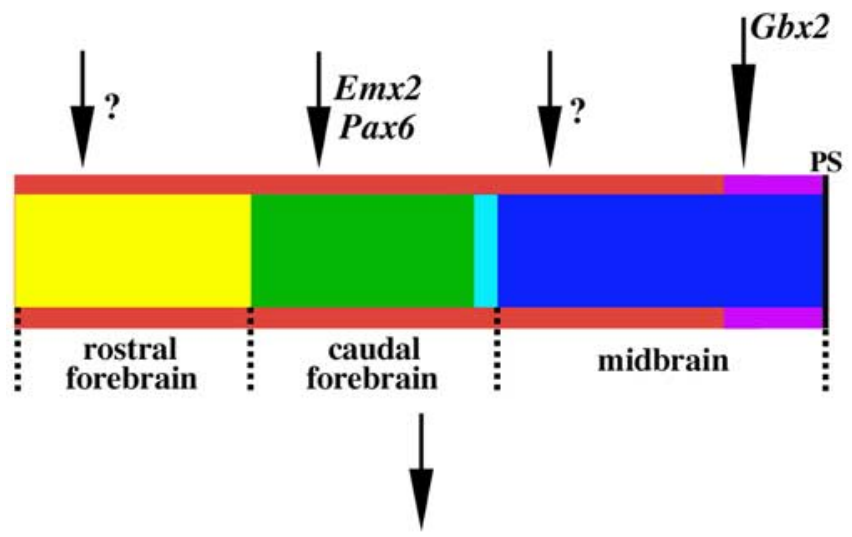

(C) 7 somite-E9.5: $O t x 2$ under FM enahncer + Otx1

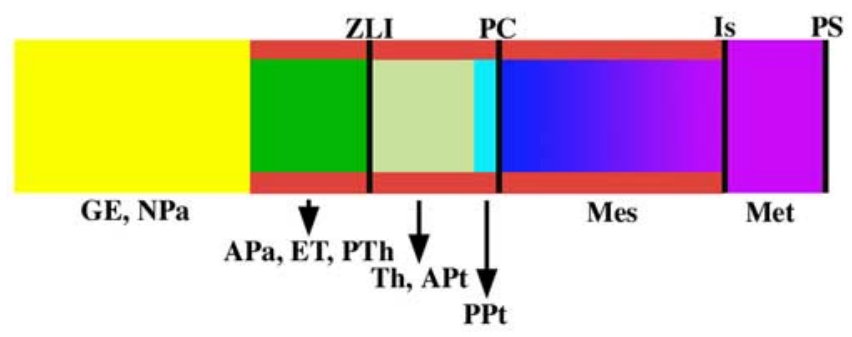

Figure 9. Schematic representation of initial regionalization of rostral brain proposed by this study. A, At the 2 somite stage, the 0 tx 2 expression (orange) in the anterior neuroectoderm that covers the entire future forebrain and midbrain is regulated by the AN enhancer; its caudal limit is obscured in front of the preotic sulcus (PS) (Kurokawa et al., 2004a). This Otx2 expression protects the anterior neuroectoderm against posteriorizing signals; its loss results in the transformation of the ectoderm to the Gbx2-positive metencephalon. B, Otx1, Emx2, and Pax6 expressions occur around the $2-4$ somite stage. We propose that at the $3-6$ somite stage, the anterior neuroectoderm rostral to the PS first differentiates into the three primordia: rostral forebrain, caudal forebrain, and midbrain. The caudal forebrain primordium corresponds to the Emx2- or Pax6-positive domain (dark green) at this stage; their expression mainly overlaps, but the Pax6 expression extends caudally beyond the Emx2 expression (light blue). To develop the caudal forebrain, Emx2 and Pax6 function redundantly, in cooperation with 0 tx 2 and 0 tx 1 . With the loss of both Emx2 and Pax6, the caudal forebrain territory remains unspecified and secondarily transforms into the tectum, as demonstrated by this study. The loss of Emx2 coupled with the hemizygous loss of Otx2 results in the loss of the caudal forebrain, except the posterior (commissure region of) pretectum (PPt) (Suda et al., 2001). The Pax6/0tx2 double mutant phenotype remains to be examined to confirm our proposal. C, The Pax6-positive and Emx2negative cells generate the posterior pretectum; the $E m \times 2$ expression is incompatible with the development of these cells as indicated by the $0 t \times 2^{+/ E m \times 2}$ knock-in mutation (Suda et al., 2001). The thalamus (Th) and anterior (non-commissure region of) pretectum (APt) cells are characterized by the loss of the Emx2 expression at E9.5 (light green); however, the continuation of the Emx2 expression is compatible with their development as demonstrated by the $0 t \times 2^{+/ E m \times 2}$ mutation. In contrast, Emx2 continues to be expressed in prethalamus (PTh), eminentia thalami (ET), and archipallium ( $\mathrm{APa}$ ) cells rostral to ZLI at E9.5 (dark green). Most dorsomedially, the caudal forebrain extends from the pretectum roof to the cortical hem, choroid plexus, and choroidal roof. The 0 tx 2 expression (orange) at this stage is governed by forebrain and midbrain enhancers (FM and FM2) that do not have activity in the rostral forebrain (yellow); they are active in the archipallium (Kurokawa et al., 2004b). The rostral forebrain generates the double mutant (Yoshida et al., 1997; Shinozaki et al., 2004). The $M s x 1, O t x 2$, and Id3 expressions are not unique to the cortical hem but also are found in the choroid plexus and roof (Fig. 7K) (Jen et al., 1997; Kurokawa et al., 2004a,b; Shinozaki et al., 2004). We consider that the incorrect Msx1, Otx2, and Id3 expression in the double mutant pallium rather represents roof character and conclude that the archipallium, choroid plexus, and cortical hem are lost in the double mutant. $L h x 5$ is a marker unique to the choroidal roof (Fig. 7I) (Shinozaki et al., 2004) and was also expressed in the double mutant pallium (Fig. 7J). Neither the Wnt3a-, Wnt5a-, nor Wnt2b-positive structure was formed, although Muzio et al. (2002) reported no changes in the expression of these markers. They also reported no change in the Wnt $8 b$ expression. In our double mutant, the Wnt $8 b$ expression was residual. The entire double mutant pallium expressed $L h x 2$ and $B F 1$; the cortical hem never expresses $L h \times 2$ or $B F 1$.

\section{Pretectum development}

In the pretectum, the anterior (non-commissure) region consisted mostly of the cells that once expressed Emx2, but the posterior (commissure) region consisted mostly of the cells that never expressed Emx2. In light of the role of Pax6 in the development of the commissure region of the pretectum (Stoykova et al., 1996; Schwarz et al., 1999) and cell lineage analysis with vital dye that indicates no cell influx from midbrain after the 5 somite stage (Inoue et al., 2000), it is most likely that the majority of cells in this region are Pax6-positive cells. Thus, it is probable that at the 3-6 somite stage, the Pax6 expression caudally extends beyond the end of the Emx2 expression, and this population of Emx2negative and Pax6-positive cells mainly generates the commissure region of the pretectum (Fig. 9); these cells also contribute, although less extensively, to the anterior pretectum. Thus, the Emx2 knock-in mutant into the Otx2 locus (Suda et al., 2001) may indicate that the Emx2 expression is incompatible with the development of these cells.

\section{Tectum duplication in a mirror image}

The presumptive caudal forebrain region developed normally at the 6 somite stage in the Emx2/Pax6 double mutant (Fig. 8B); however, the region was not specified as the caudal forebrain. Instead, it transformed into an ectopic tectum in a mirror image of the original one. Fgf 8 is expressed in the roof of the prethalamus later at E9.5, and by the Emx2 mutation, the Fgf8 expression in the commissural plate expanded caudally. Most probably this FGF8 signaling has caused the transformation, because the region is unspecified, in the double mutant. In avian, a transplantation of FGF8-soaked beads in a diencephalic region caudal but not rostral to ZLI is known to generate an ectopic midbrain in a mirror image (Crossley et al., 1996; Martinez et al., 1999). The transplantation also duplicated the tegmentum, whereas the Emx2/Pax6 double mutation did not. This is probably because the ventral region of the caudal forebrain is specified by a different genetic code.

In the Emx2/Pax6 double mutant, the caudal forebrain cells rostral to ZLI were probably not involved in the formation of the ectopic tectum. The anterior end of the ectopic En2 and EphrinA2

neopallium (NPa) and ganglionic eminences (GE). The $0 t x 2$ and $0 t x 1$ expressions at this stage protect the caudal forebrain and midbrain against posteriorizing signals. The loss of these expressions causes the transformation of the caudal forebrain and midbrain into the Gbx2positive metencephalon; however, the rostral forebrain remains established even under their loss (Kurokawa et al., 2004b). Emx 1 does not play any role in this initial brain regionalization. Is, Isthmus; Mes, mesencephalon; Met, metencephalon; PC, posterior commissure. 
expression was juxtaposed to the caudal end of the Fgf8 expression where the Shh-positive stripe ended dorsally. At E10.5, a region existed between this Shh-positive stripe and $B F 1$-positive cerebral hemispheres, whereas this region was not identifiable by E12.5 (Figs. $6 P, 8 A b$ ). The cause of the loss of this region remains for future studies; preliminary bromodeoxyuridine uptake and terminal deoxynucleotidyl transferase-mediated biotinylated UTP nick end labeling assays suggested no marked decrease in cell proliferation or increase in cell apoptosis in this region at E10.5 (data not shown). The region might be lost by posteriorization with the anterior shift of the Shh-positive stripe.

\section{References}

Bishop KM, Goudreau G, O'Leary DD (2000) Regulation of area identity in the mammalian neocortex by Emx2 and Pax6. Science 288:344-349.

Bosse A, Zulch A, Becker N, Torres M, Gomez-Skarmeta JL, Modolell J, Gruss $P$ (1997) Identification of the vertebrate Iroquois homeobox gene family with overlapping expression during early development of the nervous system. Mech Dev 69:169-181.

Bulfone P, di Blas E, Gulisano MH, Frohman MA, Martin GR, Rubenstein JLR (1993) Spatially restricted expression of Dlx-1, Dlx-2 (Tes-1), $G b x-2$, and Wnt-3 in the embryonic day 12.5 mouse forebrain defines potential transverse and longitudinal segmental boundaries. J Neurosci 13:3155-3172.

Chapouton P, Gärtner A, Götz M (1999) The role of Pax6 in restricting cell migration between developing cortex and basal ganglia. Development 126:5569-5579.

Crossley PH, Martinez S, Martin GR (1996) Midbrain development induced by FGF8 in the chick embryo. Nature 380:66-68.

Davis CA, Joyner AL (1988) Expression patterns of the homeo boxcontaining genes En-1 and En-2 and the proto-oncogene int-1 diverge during mouse development. Genes Dev 2:1736-1744.

Dressler GR, Deutsch U, Chowdhury K, Nornes HO, Gruss P (1990) Pax2, a new paired-box-containing gene and its expression in the developing excretory system. Development 109:787-795.

Echelard Y, Epstein DJ, St-Jacques B, Shen L, Mohler J, McMahon JA, McMahon AP (1993) Sonic hedgehog, a member of a family of putative signaling molecules, is implicated in the regulation of CNS polarity. Cell 75:1417-1430.

Flenniken AM, Gale NW, Yancopoulos GD, Wilkinson DG (1996) Distinct and overlapping expression patterns of ligands for Eph related receptor tyrosine kinases during mouse embryogenesis. Dev Biol 179:382-401.

Fujii T, Pichel JG, Taira M, Toyama R, Dawid IB (1994) Expression patterns of the murine LIM class homeobox gene $\lim 1$ in the developing brain and excretory system. Dev Dyn 199:73-83.

Fukuchi-Shimogori T, Grove EA (2003) Emx2 patterns the neocortex by regulating FGF positional signaling. Nat Neurosci 6:825-831.

Garel S, Marin F, Mattei MG, Vesque C, Vincent A, Charnay P (1997) Family of Ebf/Olf-1-related genes potentially involved in neuronal differentiation and regional specification in the central nervous system. Dev Dyn 210:191-205.

Grindley JC, Davidson DR, Hill RE (1995) The role of Pax-6 in eye and nasal development. Development 121:1433-1442.

Grove EA, Tole S, Limon J, Yip L, Ragsdale CW (1998) The hem of the embryonic cerebral cortex is defined by the expression of multiple Wnt genes and is compromised in Gli3-deficient mice. Development 125:2315-2325.

Heins N, Malatesta P, Cecconi F, Nakafuku M, Tucker KL, Hack MA, Chapouton P, Barde YA, Götz M (2002) Glial cells generate neurons: the role of the transcription factor Pax6. Nat Neurosci 5:308-315.

Hill RE, Jones PF, Rees AR, Sime CM, Justice MJ, Copeland NG, Jenkins NA, Graham E, Davidson DR (1989) A new family of mouse homeo boxcontaining genes: molecular structure, chromosomal location, and developmental expression of Hox-7.1. Genes Dev 3:26-37.

Hill RE, Favor J, Hogan BL, Ton CC, Saunders GF, Hanson IM, Prosser J, Jordan T, Hastie ND, van Heyningen V (1991) Mouse Small eye results from mutations in a paired-like homeobox-containing gene. Nature 354:522-525.

Inoue T, Nakamura S, Osumi N (2000) Fate mapping of the mouse prosencephalic neural plate. Dev Biol 15:373-383.
Jen Y, Manova K, Benezra R (1997) Each member of the Id gene family exhibits a unique expression pattern in mouse gastrulation and neurogenesis. Dev Dyn 208:92-106.

Kammandel B, Chowdhury K, Stoykova A, Aparicio S, Brenner S, Gruss P (1999) Distinct cis-essential modules direct the time-space pattern of the Pax6 gene activity. Dev Biol 205:79-97.

Kleinjan DA, Seawright A, Childs AJ, van Heyningen V (2004) Conserved elements in Pax6 intron 7 involved in (auto)regulation and alternative transcription. Dev Biol 265:462-477.

Kobayashi D, Kobayashi M, Matsumoto K, Ogura T, Nakafuku M, Shimamura K (2002) Early subdivisions in the neural plate define distinct competence for inductive signals. Development 129:83-93.

Korinek V, Barker N, Willert K, Molenar M, Roose J, Wagenaar G, Markman M, Lamers W, Drestree O, Clevers H (1998) Two members of the Tcf family implicated in $\mathrm{Wnt} / \beta$-catenin signaling during embryogenesis in the mouse. Mol Cell Biol 18:1248-1256.

Kurokawa D, Takasaki N, Kiyonari H, Nakayama R, Kimura-Yoshida C, Matsuo I, Aizawa S (2004a) Regulation of Otx2 expression and its functions in mouse epiblasts and anterior neuroectoderm. Development 131:3307-3317.

Kurokawa D, Kiyonari H, Nakayama R, Kimura-Yoshida C, Matsuo I, Aizawa S (2004b) Regulation of Otx2 expression and its functions in mouse forebrain and midbrain. Development 131:3319-3331.

Lagutin OV, Zhu CC, Kobayashi D, Topczewski J, Shimamura K, Puelles L, Russell HR, McKinnon PJ, Solnica-Krezel L, Oliver G (2003) Six3 repression of Wnt signaling in the anterior neuroectoderm is essential for vertebrate forebrain development. Genes Dev 17:368-379.

Larsen CW, Zeltser LM, Lumsden A (2001) Boundary formation and compartition in the avian diencephalon. J Neurosci 21:4699-4711.

Liu A, Joyner AL (2001) EN and GBX2 play essential roles downstream of FGF8 in patterning the mouse mid/hindbrain region. Development 128:181-191.

Mallamaci A, Muzio L, Chan CH, Parnavelas J, Boncinelli E (2000) Area identity shifts in the early cerebral cortex of $E m \times 2^{-/-}$mutant mice. Nat Neurosci 3:679-686.

Martinez S, Crossley PH, Cobos I, Rubenstein JL, Martin GR (1999) FGF8 induces formation of an ectopic isthmic organizer and isthmocerebellar development via a repressive effect on Otx2 expression. Development 126:1189-2000.

Martinez-Barbera JP, Rodriguez TA, Beddington RS (2000) The homeobox gene Hes $x 1$ is required in the anterior neural ectoderm for normal forebrain formation. Dev Biol 223:422-430.

Matsuo I, Kuratani S, Kimura C, Takeda N, Aizawa S (1995) Mouse Otx2 functions in the formation and patterning of rostral head. Genes Dev 9:2646-2658.

Miyamoto T, Kawahara A, Teufel A, Mukhopadhyay M, Zhao Y, Dawid IB, Westphal H (2002) Mbx, a novel mouse homeobox gene. Dev Genes Evol 212:104-106.

Muzio L, DiBenedetto B, Stoykova A, Boncinelli E, Gruss P, Mallamaci A (2002) Conservation of cerebral cortex into basal ganglia in $E m \times 2^{-1-}$ Pax6 $^{\text {Sey/Sey }}$ double-mutant mice. Nat Neurosci 5:737-745.

Oliver G, Mailhos A, Wehr R, Copeland GN, Jenkins AN, Gruss P (1995) Six3, a murine homologue of the sine oculis gene, demarcates the most anterior border of the developing neural plate and is expressed during eye development. Development 121:4045-4055.

Parr BP, Shea MJ, Vassileva G, McMahon AP (1993) Mouse Wnt genes exhibit discrete domains of expression in the early embryonic CNS and limb buds. Development 119:247-261.

Porter FD, Drago J, Xu Y, Cheema SS, Wassif C, Huang SP, Lee E, Grinberg A, Massalas JS, Bodine D, Alt F, Westphal H (1997) Lhx2, a LIM homeobox gene, is required for eye, forebrain, and definitive erythrocyte development. Development 124:2935-2944.

Puelles L, Rubenstein JL (1993) Expression patterns of homeobox and other putative regulatory genes in the embryonic mouse forebrain suggest a neuromeric organization. Trends Neurosci 16:472-479.

Puelles L, Rubenstein JL (2003) Forebrain gene expression domains and the evolving prosomeric model. Trends Neurosci 26:469-476.

Roelink H, Nusse R (1991) Expression of two members of the Wnt family during mouse development-restricted temporal and spatial patterns in the developing neural tube. Genes Dev 5:381-388.

Schwarz M, Alovarez-Bolado G, Dressler G, Urbanek P, Busslinger M, Gruss 
P (1999) Pax2/5 and Pax6 subdivide the early neural tube into three domains. Mech Dev 82:29-39.

Sheng HZ, Bertuzzi S, Chiang C, Shawlot W, Taira M, Dawid I, Westphal H (1997) Expression of murine Lhx5 suggests a role in specifying the forebrain. Dev Dyn 208:266-277.

Shinozaki K, Miyagi T, Yoshida M, Miyata T, Ogawa M, Aizawa S, Suda Y (2002) Absence of Cajal-Retzius cells and subplate neurons associated with defects of tangential cell migration from ganglionic eminence in Emx1/2 double mutant cerebral cortex. Development 129:3479-3492.

Shinozaki K, Yoshida M, Nakamura M, Aizawa S, Suda Y (2004) Emxl and Emx2 cooperate in initial phase of archipallium development. Mech Dev 121:475-489.

Simeone A, Gulisano M, Acampora D, Stornaiuolo A, Rambaldi M, Boncinelli E (1992) Two vertebrate homeobox genes related to the Drosophila empty spiracles gene are expressed in the embryonic cerebral cortex. EMBO J 11:2541-2550.

Sommer L, Ma Q, Anderson DJ (1996) neurogenins, novel family of atonalrelated bHLH transcription factors, are putative mammalian neuronal determination genes that reveal progenitor cell heterogeneity in the developing CNS and PNS. Mol Cell Neurol 8:221-241.

Soriano P (1999) Generalized lacZ expression with the ROSA26 Cre reporter strain. Nat Genet 21:70-71.

Stoykova A, Fritsch R, Walther C, Gruss P (1996) Forebrain patterning defects in Small eye mutant mice. Development 122:3453-3465.

Stoykova A, Treichel D, Hallonet M, Gruss P (2000) Pax6 modulates the dorsoventral patterning of the mammalian telencephalon. J Neurosci 20:8042-8050.

Suda Y, Matsuo I, Aizawa S (1997) Cooperation between Otx1 and Otx2 genes in developmental patterning of rostral brain. Mech Dev 69:125-141.

Suda Y, Hossain ZM, Kobayashi C, Hatano O, Yoshida M, Matsuo I, Aizawa
S (2001) Emx2 directs the development of diencephalon in cooperation with Otx2. Development 128:2433-2450.

Tao W, Lai E (1992) Telencephalon-restricted expression of BF-1, a new member of the HNF-3/fork head gene family, in the developing rat brain. Neuron 8:957-966.

Theil T, Aydin S, Koch S, Grotewold L, Rüther U (2002) Wnt and Bmp signaling cooperatively regulate graded Emx2 expression in the dorsal telencephalon. Development 129:3045-3054.

Tole S, Goudreau G, Assimacopoulos S, Grove EA (2000) Emx2 is required for growth of the hippocampus but not for hippocampal field specification. J Neurosci 20:2618-2625.

Wakasugi S, Maeda S, Shimada K, Nakashima H, Migita S (1985) Structural comparison between mouse and human prealbumin. J Biochem 98:1707-1714.

Warren N, Price DJ (1997) Roles of Pax-6 in murine diencephalic development. Development 124:1573-1582.

Wilkinson DG (1993) In situ hybridization. In: Essential developmental biology: a practical approach (Stern CD, Holland PWH, eds), pp 257-274. Oxford: IRL.

Yagi T, Tokunaga T, Furuta Y, Nada S, Yoshida M, Tsukada T, Saga Y, Takeda N, Ikawa Y, Aizawa S (1993a) A novel ES cell line, TT2, with high germline-differentiating potency. Anal Biochem 214:70-76.

Yagi T, Nada S, Watanabe N, Tamemoto H, Kohmura N, Ikawa Y, Aizawa S (1993b) A novel negative selection for homologous recombinants using diphtheria toxin A fragment gene. Anal Biochem 214:77-86.

Yamamoto M, Meno C, Sakai Y, Shiratori H, Mochida K, Ikawa Y, Saijoh Y, Hamada H (2001) The transcription factor FoxH1 (FAST) mediates Nodal signaling during anterior-posterior patterning and node formation in the mouse. Genes Dev 15:1242-1256.

Yoshida M, Suda Y, Matsuo I, Miyamoto N, Takeda N, Kuratani S, Aizawa S (1997) Emx1 and Emx2 functions in development of dorsal telencephalon. Development 124:101-111. 